\begin{tabular}{|c|c|c|c|c|c|}
\hline MUNIBE Antropologia-Arkeologia & $n^{\circ} 72$ & $203-218$ & DONOSTIA & 2021 & ISSN 1132-2217 • elSSN 2172-4555 \\
\hline
\end{tabular}

\title{
Gernikako bonbardaketa turismo kulturalaren aurrean. Antropologia sinboliko-politikotik begiratu bat ${ }^{\star}$
}

\author{
El bombardeo de Gernika frente al turismo cultural. \\ Una mirada desde la antropología simbólico-política* \\ The bombing of Gernika against cultural tourism. \\ A view from symbolic-political anthropology ${ }^{\star}$
}

GAKO-HITZAK: Memoria historikoa, kultur ondarea, turismoa, museografia

PALABRAS CLAVES: Memoria histórica, patrimonio cultural, turismo, museografía

KEY WORDS: Historical memory, cultural heritage, tourism, museography.

\section{Kepa FERNANDEZ DE LARRINOA ${ }^{(1)}$, Daniel REMENTERIA ARRUZA ${ }^{(2)}$}

\section{RESUMEN}

Esta investigación versa sobre las políticas culturales de la memoria histórica y el patrimonio cultural. Analizamos un conjunto de prácticas museográficas, memorialistas y celebratorias vinculadas a la transmisión de conocimiento histórico traumático de la Guerra Civil Española de 1936-1939. Son manifestaciones culturales creadas con el fin de expresar emociones y sufrimientos colectivos reprimidos y condenados al silencio por su pertenencia al imaginario sociopolítico de quienes resultaron vencidos en dicha contienda. Pero al mismo tiempo están empezando a formar parte de otros sistemas colectivos de representación cultural, pasando a ser elementos constituyentes de la mercadotecnia turística y la industria del ocio cultural. Hemos analizado el caso de Gernika, y nos hemos adentrado en el terreno de las representaciones y recreaciones culturales, artísticas e históricas que promueven tanto las administraciones como las asociaciones civiles locales que trabajan a favor de la restauración y salvaguarda de la memoria histórica del bombardeo de la villa.

\section{LABURPENA}

Ikerketa honetan memoria historikoaren eta kultur ondarearen politika kulturalak aztertzen ditugu, batez ere 1936-1939ko Espainiako Gerra Zibilaren ezagutza historiko traumatikoaren transmisioarekin lotutako praktika museografikoak, memorialistak eta ospakizunekoak. Emozio eta sufrimendu kolektibo erreprimituak eta isiltasunera kondenatuak adieraztekotan sortutako adierazpen kulturalak dira, gatazka horretan garaituak izan zirenen iruditeria soziopolitikokoak direlako. Baina, aldi berean, kultura-irudikapeneko beste sistema kolektibo batzuen parte izaten hasi dira, hain zuzen ere, turismo-merkataritzaren eta kultura-aisialdiaren industriaren osagaiak.

Horretarako, Gernikako kasua aztertu dugu, eta herriko bonbardaketaren memoria historikoa berreskuratzeko eta babesteko lan egiten duten administrazioek eta elkarte zibilek sustatzen dituzten irudikapen eta birsorkuntza kultural, artistiko eta historikoen eremuan murgildu gara, metodologia etnografikoa erabiliz.

\section{ABSTRACT}

This article focusses on cultural policy towards historical memory and cultural heritage. It analyzes several museum, memorialist and celebratory practices which are linked to the transmission of traumatic historical knowledge of the Spanish Civil War of 1936-1939. They are cultural manifestations created in order to express repressed collective emotions and sufferings, most o them condemned to silence due to their belonging to the sociopolitical imaginary of those defeated in the contest. But at the same time, they are beginning to form part of other collective systems of cultural representation, then to become constituent elements of the tourist marketing and cultural leisure industry.

Based on ethnographic research, the article looks at Gernika (Bizkaia) where the authors study a significant array of cultural, artistic and historical representations as well as recreations promoted by both public administration and the local civil associations that work in favor of the restoration and safeguard of the historical memory of the bombardment of the village.

\footnotetext{
* Lan hau 2017ko irailetik 2018ko uztailera bitartean Eusko Jaurlaritzako Kultura Ondarearen Zuzendaritzak finantziatutako landa-ikerketa batean oinarritzen da. Ikerketa, antropologia etnografikoaren jarraibide metodologiko bereizgarriak jarraituz egin zen. Horrez gain, ondare kulturalari eta memoria historikoari buruzko jarduera pribatuak eta publikoak kudeatzeko idatzitako lege-, arau- eta administrazio-dokumentuak aztertu dira.
}

(1) Lera-Ikergunea (Iruñea). kepa.fernandezdelarrinoa@unavarra.es

(2) Lera-Ikergunea (Iruñea). daniremen@hotmail.com 


\section{SARRERA. EUSKAL NEOLIBERALISMO KUL- TURAL AURRERAKOIAREN KRITIKA ETNO- GRAFIKORAKO OHARRAK}

Saiakera hau kultur ondareari eta memoria historikoari buruzkoa da. Ezagutza historiko traumatikoaren transmisioari lotutako hainbat praktika museografiko, memorialista zein ospakizun aztertzen ditu. Oro har, 1936-1939ko Espainiako Gerra Zibilean garaituak suertatu zirenen irudimen soziopolitikoari dagozkion -erreprimitutako eta isiltasunera kondenatutako- emozio eta sufrimendu kolektiboak adierazteko nahian sortutako kultura-adierazpenak dira. Baina gerta daiteke, aldi berean, babesik gabeko zibilen aurkako gehiegikeria militarren irudikapen kultural horiek, gaur egun memoria historiko gisa katalogaturik daudenak, kultur irudikapenerako beste sistema kolektibo batzuen parte izatea. Adibidez, turismoaren mende dagoen tokiko ekonomiari laguntza formala emateko sistema osatzen duten elementuak izan daitezke.

Horren ondorioz, ez dira beti guztiz zehatzak izaten sozializazio publikoa eta ezagutza historikoa, gerraren sufrimenduaren pedagogia, kalteturik gertatu zirenen kalte-ordain moral eta politikoa, eta aisialdi kulturalaren industria elkarrengandik bereizten dituzten ildo zibilak, enpresakoak eta gobernukoak.

Horregatik, Ian honetan memoria historikoaren kultura-politikei buruz galdetu diogu geure buruari, eta, horri erantzuteko, memoria historikoa berritzearen eta zaintzearen alde lan egiten duten tokiko elkarte zibilek sustatzen dituzten errepresentazio eta birsortze kultural, artistiko eta historikoen eremuan murgildu gara.

Talde horiek egia, justizia eta erreparazioa estandarte politiko gisa daramaten elkarteak dira. Aldian-aldian, beren herrietan gertaera haien oroitzapenerako ekintzak antolatzen dituzten taldeak dira. Horrela, diktadura frankistaren hamarkadetan eta demokrazia parlamentariorako trantsizio politikoaren urteetan erreprimitutako eta jazarritako esanahi eta emozioak gogorarazten dituzte.

\subsection{Eremu geografikoa}

Gaur egun, 1930eko hamarkadako bigarren bosturtekoan lehen borroka-lerroan egon ziren Bizkaiko, Gipuzkoako eta Arabako herri askok, armada frankistak Bilborantz egin zuen erasoaldiari aurre egiteko gertaeren oroitzapen haiek gogora ekartzen dituzte. "Memoria historikoaren berreskuratze"-aren esparru-izenpean, komunitate batzuek tokiko memoria historikoa interpretatzeko museoak eta zentroak ezartzen dituzte, eta borrokaren lekuak seinaleztatzen dituzte panel argigarriak erabiliz, edota plazetan eta kaleetan plakak jarriz.

Beste batzuek bisita gidatuak antolatzen dituzte gerrako lekuetara, kasu batzuetan azalpen dramatizatuekin batera etortzen direnak, edo une tragiko hartako gerra-gertakariren bat in situ eta zuzenean erreproduzitzen dute. Beste batzuek biziraun zutenei edo urte haietako eraso militar eta paramilitarren ondorio fisiko, moral eta politikoak pairatu zituztenen zuzeneko senideei omenaldiak antolatzen dituzte. Beste batzuek azterketaeta dibulgazio-jardunaldiak koordinatzen dituzte, eta oroitzapenezko liburuxkak eta ikerketa-liburuak argitaratu. Horiekin batera, hobiak eta gorpuak aurkitzen dituzte, lurpetik ateratzeko, identifikatzeko eta senideei itzultzeko. Hiru gai horien nahasketa ekintza kulturaleko eremu indartsua da gaur egun, garrantzi sozial, politiko eta historikoz betea.

Gerra, gerraurreko eta gerraosteko urteen oroitzapenei lotutako kultura-proiektuek, beraz, lehen ez zuten protagonismo publikoa hartu dute. Horren ondorioz, Euskal Autonomia Erkidegoan ondare esparru kultural berri bat estreinatu da, errebindikazio mugimendu sozial baten eta bi gorputz legegileren elkargunetik sortua: batetik, memoria historikoari dagokiona, eta, bestetik, kultur ondarearen kudeaketa administratiboari lotutakoa. Hiru gai hauen nahasketak, gaur egun, kultur ekintzaz beteriko eremu sendoa osatzen du, garrantzi sozial, politiko eta historikoz betea.

Hemen, horrela bideratutako zenbait jarduera eta programa kulturalen azterketa etnografikoa aurkezten dugu. Prozesu horiek ondarearen ikuspegitik balioan jarri izatearen aztertzeaz gain, era berean, kulturaren, kultur ondarearen eta memoria historikoaren adierazpenen lotura kontzeptuala eta formala aztertzen dugu, alde batetik, antropologia-azterlanetan eztabaidatzen diren heinean, eta, bestetik, gobernuaren kultura-politiken administrazio-ideiekin parekatzen diren neurrian. Beraz, memoria historikoaren eta kultur ondarearen arteko loturari buruz galdetzen diogu geure buruari.

Horretarako, metodo etnografikoaren laguntzaz, ikusi dugu 1936-1939ko gerrako memoria kulturala, leku, objektu, erritu, pertsona, talde, sinbolo, idazki, kantu, dantza, lore eskaintza, musika, meditazio, isiltasun, oihu, [...] bisita turistiko eta argazki kameren mihiztadura bat dela.

Beraz, dualtasun ukaezin batetik abiatzen gara: alde batetik, gizabanakook ez gara memoriaz autonomoak; bestetik, giza taldeok -erakundeek, alderdi politikoek, elkarte zibilek, familiek- ez dugu, kolektiboak osatzen ditugun aldetik, memoria komuneko modulu mental bat. Baina, modu esanguratsuan, geure buruaren eta besteen errepresentazio kulturalak antolatzeko gaitasuna dugu ${ }^{1}$.

Eta gai horrek galdera bikoitz honetara garamatza: nola antolatzen dituzte taldeek, norbanako partikularrek gogoratzeko erabiltzen ditugun gizarte-baliabideak eta kultura-tresnak?; nola lotzen eta elkarreragiten dute

${ }_{1}^{1}$ Neurozientzia arloan, teoria honi, gogamenaren teoria deritzote. / In the field of neuroscience, this theory is called the theory of mind (Mitchell 1997). 


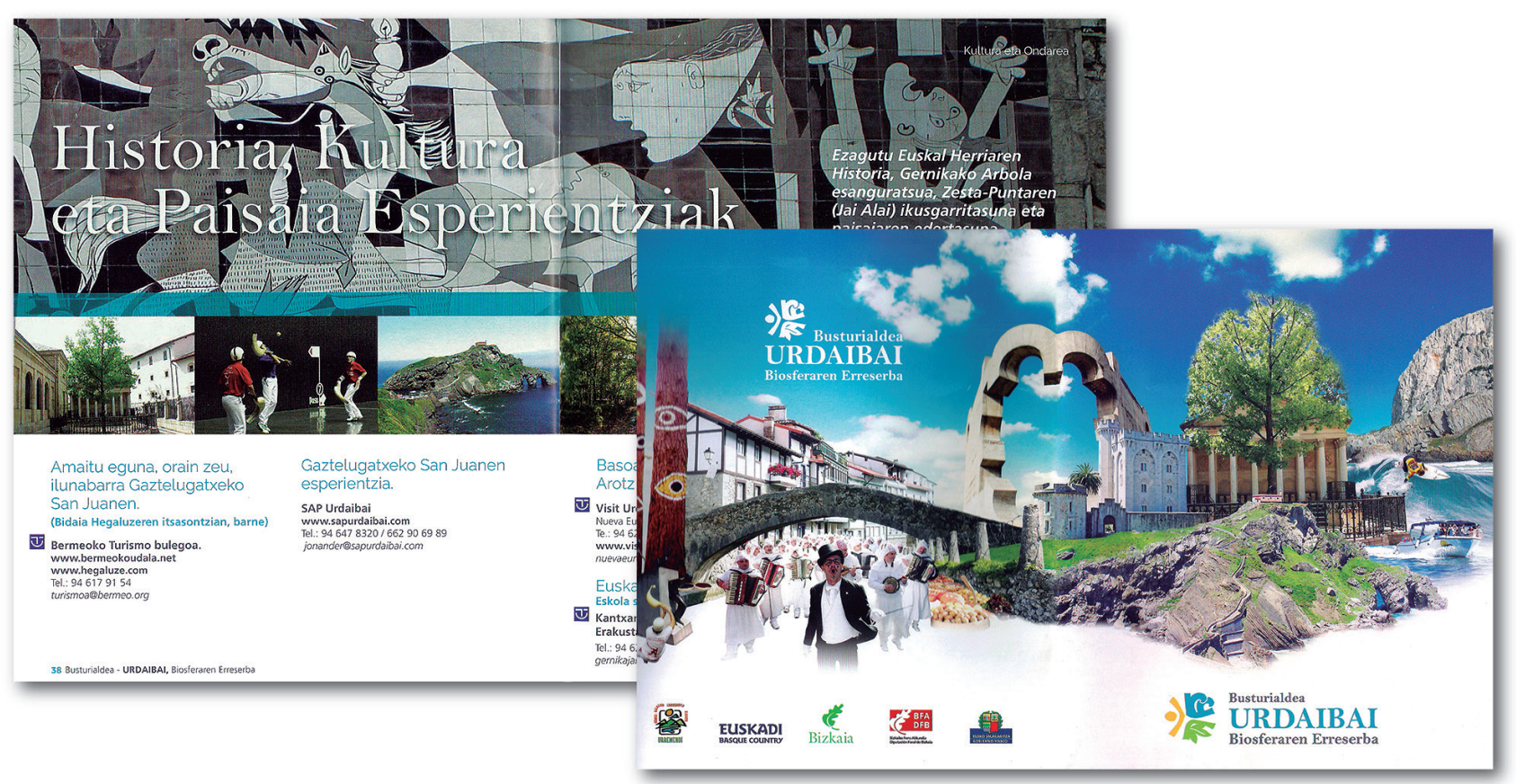

Fig.1- Fig. 2. Turismo-liburuxka, Busturialdea-Urdaibai Biosferaren erreserba. Historia, Kultura eta Paisaia experientziak (Urremendi, Nueva Europa S. L.). / Tourist brochure, Busturia-Urdaibai Biosphere Reserve. History, Culture and Landscape Experiences (Urremendi, Nueva Europa S.L.).

gizabanakoek gizarte- eta kultura-baliabide horietan, eta nola erabiltzen dituzte politikoki eta instrumentalki baliabide horiek? Puntu horretan kokatu dugu 19361939ko gerraren memoria historikoaren azterketa.

Hasiera batean, Euskal Autonomia Erkidegoko hiru lurralde historikoetako hiru eremutan egin genuen gure berton bertoko ikerketa: 1) Zigoitia eta bere eskualdea (Araba); 2) Elgeta eta Elgoibar (Gipuzkoa); 3) Gernika eta bere eskualdea (Bizkaia). Azkenean, Gernikaldean zentratu ginen, bereziki herrian bertan. Gernikako bonbardaketaren memoria historikoa eraikitzearen prozesua, kultur ondareari dagokionez, hamarkada batzuk lehenagotik datorren kontua da. Oro har, museografiak eta kultura-erakustaldiak dira (batez ere historikoak, antzerkikoak eta artistikoak), eta, nahiz eta jatorria gerra-indarkeriaren doakotasunean eta gizarte zibilaren sufrimenduan izan, nazioz gaindiko eta kulturen arteko "bakearen kultura"-ren ideian oinarritzen dira. Gure azterlanak agerian uzten du Gernikako bonbardaketaren ondare-eraikuntza garaikide hori, bakerako kultura-adierazpen publikoen terminoetan, beste ondare-eraikuntza mota batzuekin batera gertatzen dela, hala nola ekoturismoa eta kultura-turismoarekin.

\subsection{Marko teoriko eta interpretatiboa}

1936-1939ko gerran garaitutakoen heriotzen inguruabarrek eta haien ondorioak historia politikoaren kontzeptuari garrantzi handia eman dion kultur memoria publikoaren sistema batera eraman dute.

Espainian 1936ko estatu-kolpe militarrari eta ondorengo hamarkadetan errepresio zibilari lotutako memo- ria eta ahanztura mekanismoak aztertu dituztenek ez dute zalantzarik izan Emile Durkheimek (1858-1917) utzitako Frantziako kanon soziologikoaren azalpen-eraginkortasuna aitortzeko. Hori dela eta, Frantzian, XX. mende hasierako ospakizun publikoei eta giza irudikapen kolektiboei buruzko ikerketa antropologiko funtzionalistetan oinarrituta, Maurice Halbwachs (1877-1945) eta Pierre Nora (1931-) historialari ospetsuak hirigintza publikoaren, nortasun politikoaren eta boterearen azterketan murgildu ziren. Frantziako kultura ofizialaren eta instituzionalaren esparruan zentratu baziren ere, beren ikerketek giza memoria esploratzeko eredu sui generis bat sortu dute, "Durkheim-Halbwachs-Nora eredua" izenekoa hain zuzen (Brockmeier, 2018).

Ikerketa-esparru hori memoriaren kontzeptu esplizituki kolektibo batean oinarritzen da. Kontzeptu hori zehaztea, batetik, espazio publikoen antolamenduaren eta, bestetik, espazio horietan objektu materialak modu ordenatuan kokatu eta banatzearen arteko harreman politiko eta sinboliko-kognitiboan datza (Fernandez de Larrinoa, 2017). Eredu horrek azpimarratzen du ezinezkoa dela harekin batera doan interpretazio-prozesuaren memoria besterentzea. Hau da, memoriak esanahia edo zentzua hartzen du, gizabanakoen arteko prozesu dialogiko batean sartzen den momentuan (Brockmeier 2018:61). Gogoratzea, azken batean, gertaera soziala da. Hizkera antropologiko batean esanda, giza memoria ekintza kulturala da, hau da, interpretazio-ekintzen sintesia.

Lehen aipatu dugu Gernikako bonbardaketaren oroitzapenak ondare-hizkuntzak, testu-tratamenduak eta monumentu eskultorikoei, arte-piezei, kanpoalde 
zabaleko sorkuntza esperimentalei eta diseinu museografikoari lotutako azalpen-irudiak erabili dituela. Seinaleztatutako espazioak eta ibilbideak ere nabarmendu dituzte, baita antzezpenak eta berreraikuntzak ere. Era berean, elkarte zibilek eta ikerketa-zentroek ezagutza bilatzeko eta sortzeko duten zeregina dago, bai eta ahozko, ikusizko eta idatzizko zabalkundea ere.

Bada, hala ere, gure azterlanak jasotzen duen beste gogoeta bat: 1936-1939ko gerrako "gernikar" memoria historikoaren kultura-ondarizazioko prozesura jotzea, eta Estatu kulturala eta pribatizazioaren, eta kulturaren kontsumoaren administrazio-nozioekin lotuta aztertzea. XX. mendetik XXI. mendera bitarteko jauziak ekonomia kapitalista finantzario globalaren eredu bat ezarri du, non kultura nozioaren eremu semantikoa birformulatuta geratu den: jada ez ditu izendatzen gizarte-erabilerako balioaren arabera epaitzen diren harreman multzoak; kultura terminoa, gaur egun, merkataritza-eremu bat da, aldaketa ekonomikoko balioari begira epaitua. Espainia Europar Batasunean sartzeak kultura-harremanen giza eremura MBA (Master in Business Administration) lengoaia eramatea ekarri zuen. Pentsamenduak eta jarrera neoliberaleko ekintza ekonomikoak "kultura-ekintza" kontzeptua ezarri zuten, beste kontzeptu baten barruan, "kultura-industria". Elkarrekiko esanahiak kultura-politika publikoak nahiz enpresa-estrategia pribatuak antolatzen ditu (Fernandez de Larrinoa 2011).

Saiakera honetan argudiatzen da Gernikako bonbardaketaren memoria historikoaren ondare kulturala bilakatze prozesua arau-prozesu gisa, prozesu ekonomiko gisa eta herritarren prozesu gisa azter daitekeela. Hiru prozesu horiek analisi bereiziak behar dituzte, eta, aldi berean, elkarren arteko alderaketa. Hori azaltzeko, alde batetik, Pierre Bourdieu eta Bruce Kapfererrek kultura kontzeptuaren inguruan egindako kritika antropologikoetara jo dugu. Bestetik, kulturaren kudeaketa administratibo nazionalaren eta nazioartekoaren kritika antropologikoak egin dituzten Marc Fujimori eta Dean MacCannell pentsalarien argudioetara, besteak beste. Soziologia kulturalera ere jo dugu, batez ere Gilles Lipovetsky eta Jean Serroyren La estetización del mundo obran azaldutako zehaztapenetara, non kapitalismo artistikoa, kapitalismo sortzailea eta kapitalismo transestetikoa bezalako nozioen esanahia xehatzen den. Funtsean, autore hauek kosmos artistiko hipermodernoaren sorkuntza-legeak -helburu emozionaletarako-, hipermodernitatearen ekonomiekin uztarketa aztertzen dute.

Argudio horiek ikusita, tokiko kulturen tratamendu funtzionarialaren azterketa antropologiko batean saihestezinak diren bi gairi buruz galderak egin dizkiogu geure buruari: zenbaterainokoak dira kultura-ondasun eta kultura-zerbitzuen ekoizpenari eta kontsumoari buruzko gobernuaren neurri hauek "gizarte-entretenimendua eta partaidetza-entretenimendua" ardatz dituen ekonomia politikoa "demokratikoki" asetzeko asmo hutsagatik erabiltzen? Tokiko turismoaren sustapen administratiboa al da kultura berezitasunaren deuseztapenarenerako bide postmodernoa? Beste era batera esanda: 1936-1939ko gerrako memoria historikoaren kultura-irudikapenak kultur kontsumoko programa eta ibilbide turistikoetan sartzea, bere garaian publikoki agertzean eskatzen zuen dimentsio politikoa deuseztatzeko tranpolina al da?

Jean eta John Comaroff hegoafrikar senar-emazteek "etnizitatea" logo korporatiboaren merkataritza-potentzialari buruz itaundu zioten euren buruari 2009an, pentsamendu soziokulturala antolatzeko sistema neoliberal baten barruan.
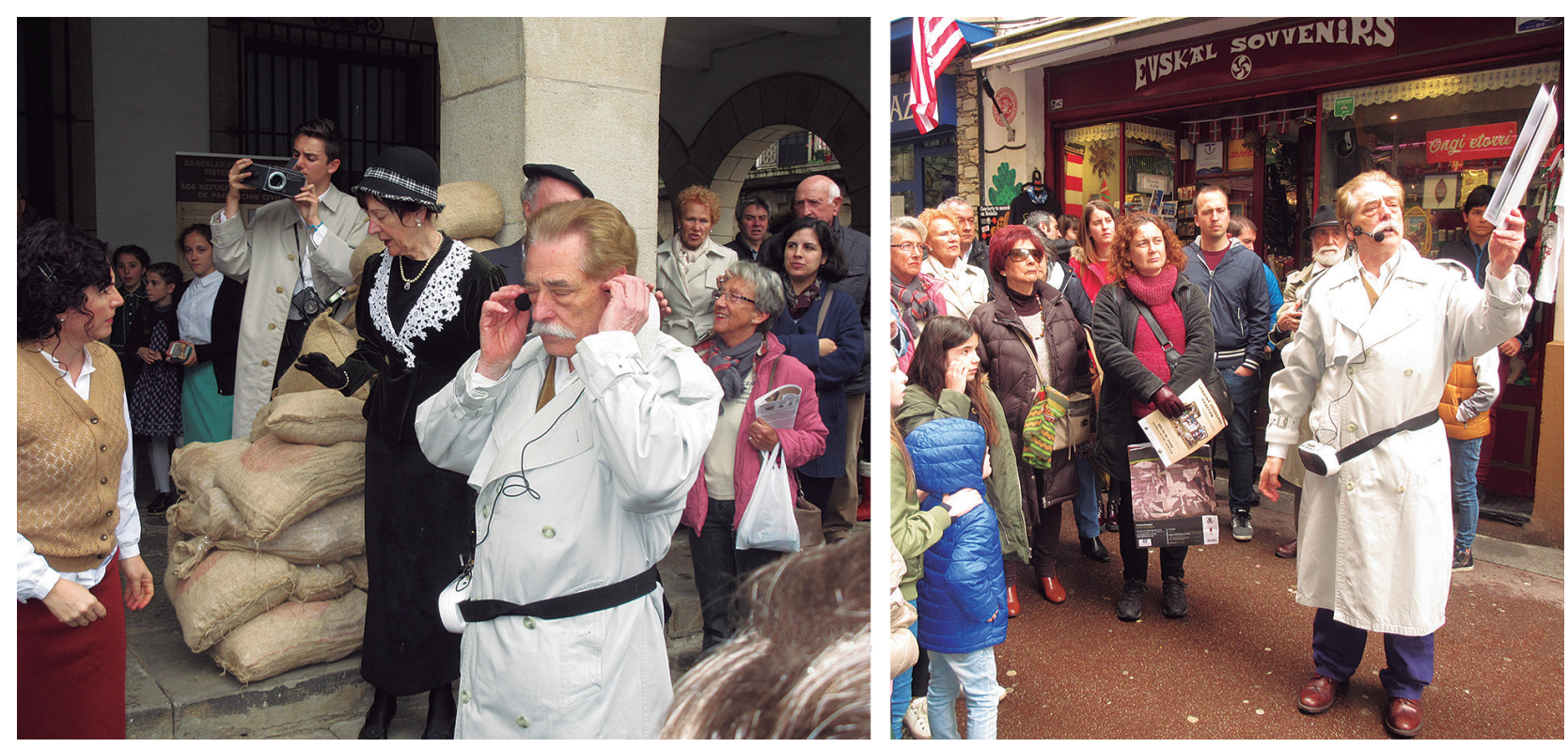

Fig.3- Fig. 4. Gernika Udabarri haretan. Babesleku antiaereotara bisita gidatua Gernikazaharraren eskutik (autorea, K. Fernández de Larrinoa). / Guided visit to the bomb shelters by the local association Gernikazaharra (photographs by Kepa Fernandez de Larrinoa). 
1936-1939ko Gerra Zibileko izugarrikerien tokiko memoria historikoek aurrera egiten dute kultura-ondarizazioko prozesuetan, eta aurreko hamarkadetan baino arau-joera handiagoarekin kudeatzen dira.

Estatuko administrazioan duen inskripzio-maila handituz doa. Eta aldi berean, Estatuak berak, tokiko biztanleen garapen ekonomikoak sustatzen ditu, neurri handi batean, haien kultura-balioak kontsumitzeko dinamizaziora bideratuz.

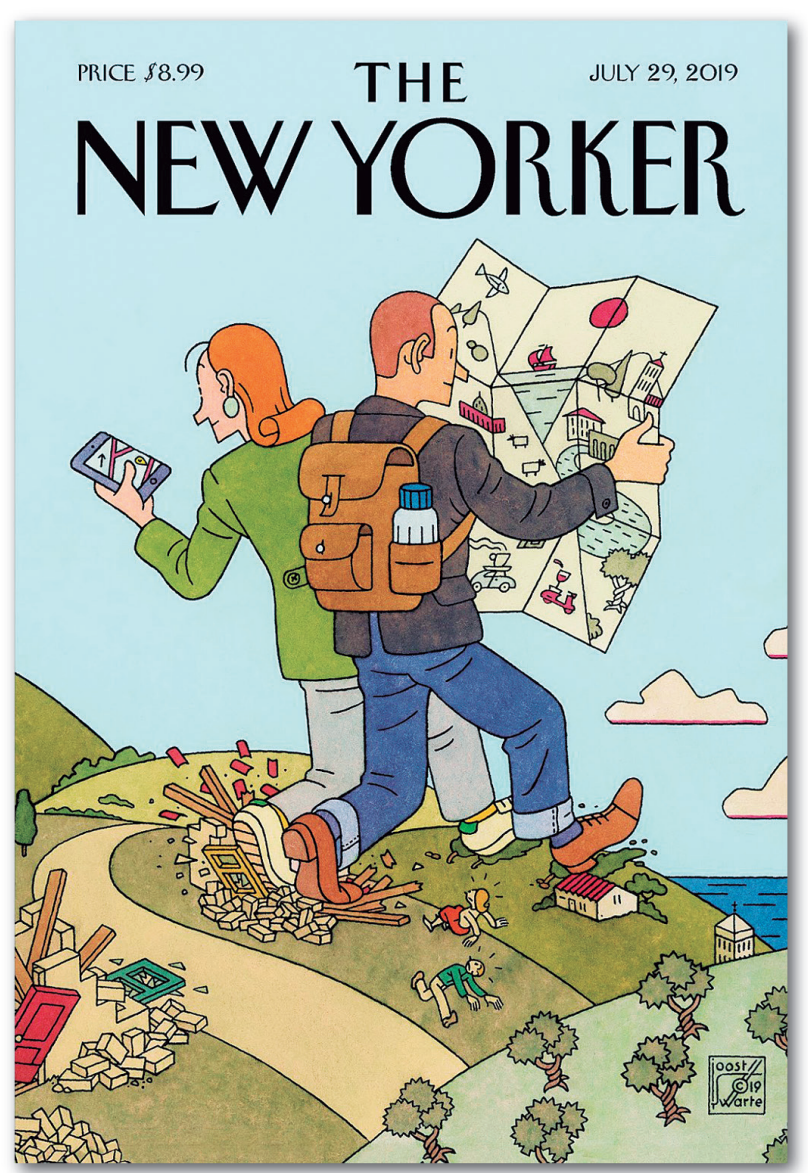

Fig.5. The New Yorker aldizkariaren azala. Power Trip, Joost Swarte-ren ilustrazioa (iturria, on-line). / Front page, New Yorker. Power Trip. Ilustración de Joost Swarte (Source: on-line).

\subsection{Argumentu-funtsa}

Gizarte antropologiatik eta metodo etnografikotik Gernikaldeko memoria historikoaren kultura-irudikapenen ondarizazio prozesuak aztertzeak bi jarduera-ildo teoriko-praktikoen konbinazioa erakusten du. Alde batetik, kutsu kontsumistadun kultura-politiketan gorakada bat hautematen da. Hori bereziki nabarmena izan da Euskal Herrian, Eusko Jaurlaritzako ordezkarien eta Solomon R. Guggenheim Fundazioko ordezkarien arteko akordiotik abiatuta. Akordioak 1997an Bilbon arte modernoaren nazioarteko museo bat jartzea ekarri zuen. Helburua hiriko kultura-zerbitzuen abangoardiatik eus- kal ekonomiaren "tertziarizazioan" laguntzea zen (Zulaika 2002, 2014). Hau da, Euskal Autonomia Erkidegoan gizarte-harremanen sistema ekonomiko bat txertatzeko helburuarekin ezarri zen, hilzorian zegoen siderometalurgiaren sistema ordezteko, irudi kulturalak barne- eta kanpo-mailan ekoiztuz eta kontsumituz.

Izan ere, Bizkaiko Foru Aldundiak 2000ko hamarkadaren amaieran Gernikaldea eskualderako mega-proiektu kultural bat iragarri zuen: Urdaibain bigarren Guggenheim bat ezartzea. Bere izateko arrazoia eskualdeko garapen ekonomikoaren premia nagusi bati laguntzea zen, ekoturismoa gehiago indartuz, hau da, natura, artea, turismoa eta tokiko garapena, enpresa-kudeaketa neoliberalean bilduta (Kalin, 2006; Stallabrass, 2007; Mosedale, 2016). "Guggenheim" kultur kontsumorako New Yorkeko markak eta "Biosfera Erreserba" kontsumo ekologikorako gobernu arteko markak, elkarren arteko konbinazioan, tokiko garapenerako ekonomia bat adierazten zuten: ekoturismo kulturala (Rementeria 2015, 2016). Giza harremanen esparru guztiak bereganatzeko nahi horretan, neoliberalismo ekonomikoak adierazpen zehatz bat eman dio nazioarteko estatu eta erakundeen administrazio-hizkuntzari: ekosistemako kultura-zerbitzuak (Milcu, Hanspach, Abson eta Fischer, 2013).

Tokiko gizartearen oposizio handia izan zuen frankizia proiektu hura ur administratibo lohitsuetan hondoratuta geratu zen. Hala eta guztiz ere, 1984az geroztik paisaia-benetakotasunaren ziurtagiria eta Nazio Batuen administrazio-zigilua dituen Biosferaren Erreserbaren erreklamo estetikoak ekoturismo-industria bat sustatzen jarraitzen du. Aldi berean, beste alde batetik, 1937ko apirilaren 26ko bonbardaketa gogoratzeko aldarrikapen politikoa eta Gernikako hiribilduaren suntsipenari buruzko gezur frankistak daude. Horrela, bonbardaketen sufrimendu zibila, bakearen pedagogia eta bizikidetza-txartel global bihurtu da museoetan. Atzean gelditzen dira gizabidezko mobilizazio eta oinarrizko gizarte-erakundeak. Busturialdeko Defentsarako Koordinakundea eta Gernikako Ekologia tailerra izan ziren, 1970eko hamarkadan paduren ekosistema hiri-industriako lurzoru zabal bihurtzeko plana geldiarazteko sortu zirenak. Mugimendu autoantolatu haiek, merkatu-ekonomia kapitalistatik kanpo, kontzientzia ekologiko politikoak sustatu zituzten. Atzean geratzen da, baita ere, tokiko elkarte zibilen lana, 1998an aire-erasoaren museo bat sortu eta 2002an Bakearen Museo gisa birformulatzea lortu zutenak. Frankismoaren aurkako militantziaz haragoko kontzientzia politikoak sustatu zituzten, eta internazionalismo antimilitaristarekin bat egin zuten. Eta atzean, baita, Astra izeneko armen fabrika bat dago, Gernikan industria garrantzitsua izan zena 1913 eta 1997 artean, itxi zen urtera artea. Bertan behera utzita, eraikina "okupatu" egin zuten, onura soziala emateko asmoz. Gaur egun, kultur gune "alternatiboa" da, autogestioaren printzipioek gidatua.

Hala ere, Gernika, munduko gatazka belikoen konponbidean elkarrizketa etikoaren alde, euskal sus- 
traiko marka diskurtsibo batekin argi identifikatzeko erabiltzen diren errepresentazio eta sorkuntza kultural publikoen amalgama horren azpian, modu adierazgarrian Estatu Espainiarraren nazioarteko armen merkataritza handiena ezkutatzen da. 2000ko txosten baten arabera, Espainiak atzerrira esportatzen zuen arma arinen \% 50 Euskal Autonomia Erkidegotik irteten zen. Urte hartan 11.000 milioi pezeta saldu ziren eta euskal enpresek 5.000 milioirekin parte hartu zuten. Iturri horren arabera, arma arinek "bost biktimetatik lau" eragiten dituzte "mundu osoko liskar armatuetan". Izan ere, Euskal Autonomia Erkidegoak Espainiako arma arinen esportazioaren buru izaten jarraitzen zuen 2016an, eta urte horretan bakarrik 84,5 milioi euro baino gehiago fakturatu zituen (Chicote, 2017) ${ }^{3}$.

Beraz, 1990eko hamarkadaren amaiera eta 2000ko hamarkadaren bilakaeraren artean, Gernikan 1936-1939ko gerraren eraginaren ikono aurrerakoi eta adiskidetzaile bat ezarri da, "Bakearen eta elkarrizketaren kultura" nozioarekin estuki lotuta dagoen hiribilduaren irudi publikoaren moldaketan oinarrituta. Horrez gain, 1936-1939ko gerrako memoria historikoaren kultura-irudikapenak aisialdiko turismoaren, kultura-ikuskizunaren eta ingurumen-iraunkortasunaren zerrendetan argitaratzen dira. Horrela, gizarte-ekintza aurrerakoia eta pentsamendu ekonomiko neoliberala gurutzatu egiten dira.

Gernikara iristen den bisitariari ezagutzera ematen zaizkion kultura-erreferenteak bi ardatz tematiko handiren inguruan antolatzen dira: 1) bere sustraiak historiaurrean hondoratzen dituen ekosistemari datxekion kultura-berezitasuna; eta 2) gerrako indarkeria-ekintza gaizto batean gertatutako hiribilduaren suntsipen materiala. Eta zera gertatzen da: Gernikaldea ez dago kultura-ekoturismoaren merkataritza-mapatik kanpo, ezta Euskal Herria ere gerrako negozioen mapatik kanpo, ezta elkartasun altermundistaren mapatik ere. Nola interpretatu behar ditugu memoria historikoaren kultura-ondarizazioko prozesuan uztartzen diren politika publikoak, herritarren gizarte-ekintza, estrategia ekonomiko pribatuak eta politika publikoak? Alde batetik, frankismoaren aurkako borrokari lotutako aurrerakoitasun politikoa eta iraganeko gezurrak eraisteko misio politikoa daude; bestetik, ingurumenaren defentsaren progresismo ekologikoa hormigoi armatuaren aurrerapenaren aurrean; eta beste alde batetik, kulturaren eta kulturaren lurraldeen merkatu estetiko-kontsumistan txertatutako politika sozioekonomiko neoliberalen aplikazioa.

Bitxia bada ere, konbinazio horrek itxura aurrerakoia duten ondare-diseinu neoliberalak argitzen ditu, eta, beraz, oroimen historikoa eta kultur ondarea batera aztertzeko proposatzen duen saiakera honetan, hurrengo gogoeta galdera hau egitera gonbidatzen da: ea ez ote den euskal gizartean kultura-pentsamendu bat ezarri, kultura-pentsamendu hutsala, sakonez izaera neoliberalekoa, baina aurrerakoitasun soziopolitikoz estalirikoa, hain zuzen.

\section{ONDARE KULTURALAREN ETA MEMORIA HIS- TORIKOAREN ELKAR TOPAKETA}

Gizakien ezagutzaren diziplina moduan hasi zenetik, antropologia sozialak lotura handia izan du kultura-adierazpenen azterketarekin. Gaur egun onartuta dago ondare kulturalaren nozioak eragin izan duela objektu materialen hautaketaren, eskuratzearen, zaintzaren eta legatuaren inguruan, eta hori normalean lotzen zaizkien ideia, konbentzio sozial eta sinesmen kulturalekin batera gertatzen da (Ames 1992; Sherman eta Rogoff eds. 1994; Simpson 1996).

Bereziki aldakorra den nozioa da, une historikoaren eta gizarte-taldearen arabera aldatzen diren giza taldeak sortutako praktika sozialei eta kultura-trebakuntzei baitagokie. Ondorioz, gaur egungo antropologo sozia-

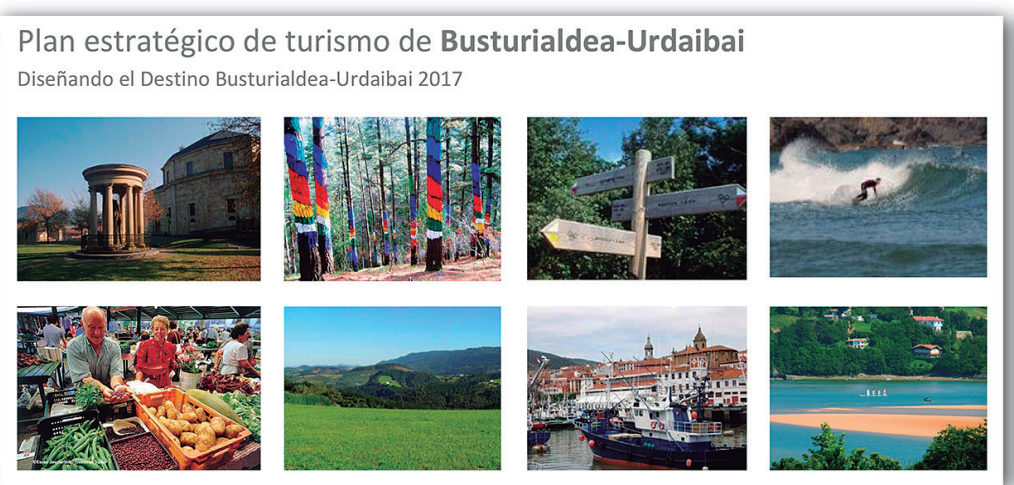

Fig.6. Busturialdea-Urdaibai-ko turismo plan estrategikoaren irudia. / Image of the Strategic Tourism Plan of Busturia-Urdaibai.

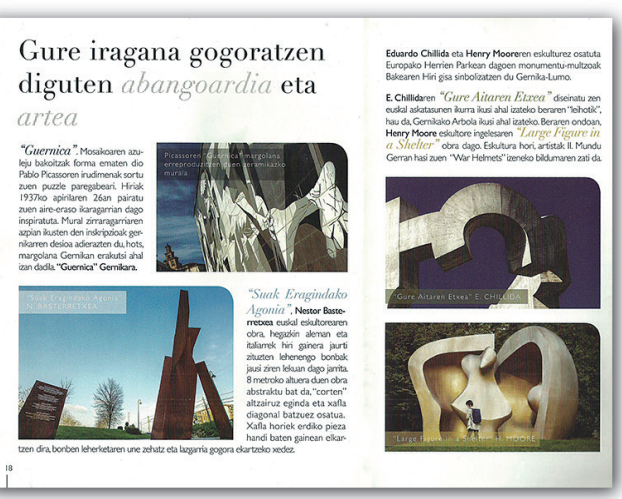

Fig.7. Gure iragana gogoratzen diguten abangoardia eta artea (turismo-liburuxka). / Avant-garde and art that recall our past (Tourist brochure).

\footnotetext{
2 El País egunkarian (2000). https://elpais.com/diario/2000/03/15/paisvasco/953152801_850215.html.

${ }^{3}$ https://www.abc.es/espana/abci-cataluna-exporta-cuarta-parte-armas-y-municion-vende-espana-201708292150_noticia.html.
} 
lek elkarri lotutako bi gai azpimarratzen dituzte: kultura-ondarea kultura-irudikapenerako modu bat dela; eta, era berean, gizarte-eraikuntzarako bitarteko bat dela (Morphy 1991; Dilworth 1996; Errington 1998; Strother 1998). Bestela esanda, ondare kulturala irudi kulturalen eta errealitate sozialen eraikitzailea eta era berean eraiketa bat da. Gauza bera esan daiteke "memoria historikoa" adierazpenarekin batera datozen praktika sozialei eta interpretazio intelektualei buruz.

Esate baterako, oroitzapenezko museoak museo historiografikoak dira, eta horien barneko kultura-irudikapenak XX. mendeko proiektu politiko totalitaristak (bai komunistak, bai faxistak eta bai etniko edo erlijiosoak) markatu dituen berezko izua azpimarratzen du. Kezka historiografiko etengabean, "benetakotasuna" gogora ekartzeko betebeharra dute, eta, beraz, "sufrimendu-espazioak" birsortzeko eta nabarmentzeko premia programatikoa ikusten dute, non bisitariek urratutako bizitzak eta kaltearen irudikapenak zuzenean hauteman ditzaketen. Eta horrekin batera, indarkeria politikoak oroitzeko museoak bizirik dirautenentzako zein haien familientzako espazioak dira.

Hau da, bilketa eta introspekzio pertsonala aurkitzeko espazioak eratzen dituzte, eta, era berean, Estatuak biktimekiko duen betebehar instituzionala publikoki adierazteko lekuak dira, haiekiko jokabidea okerra eta justifikaezina dela herritarren aurrean aitortuz, eta errepresaliatuei garai hartan kendu zitzaien duintasuna itzultzen saiatuz. Baina, zein "bestetasun" eta "berberatasun" eraikitzen, estaltzen edo hondatzen dituzte memoria historikoaren museoek? Lehenik eta behin, gizabanakoen talde espezifikoen gain eragindako tratu ankerraren aurkako museoak direla aipatu beharrean gaude: alegia, nortasun kolektibo marjinalak, azpiratuak, baztertuak, isilduak edo hautsituak berreraikitzeko museoak dira.

Gure azterketari dagokionez, esan behar dugu modernitatearen, kultura-aurkikuntzaren eta Ilustrazioaren ideiek, batetik, eta post-modernitatearen, sormenaren eta kultura-erakustaldiaren ideiek, bestetik, esanahi politiko berezia hartzen dutela memoria historikoaren ikuspegitik ikusten direnean. Beraz, Ilustrazioa eta esplotazioa eta genozidio ekonomikoa txanpon beraren aurpegia eta gurutzea dira. Era berean, kapitalismo neoliberalak kultura-sormenaren nozioa txertatu du bere baitan, eta bere esanahi-eremua merkataritza-salgaien transakzioen merkatuan txertatu beharreko produktu eta zerbitzu berrietara murriztu du.

\section{MEMORIAREN POLITIKAK ETA ESTRATE- GIAK. MUSEOGRAFIA, MEMORIA ETA ANTIMILI- TARISMOA GERNIKAN}

Aipatu dugun bezala, ikerketa multikokatu honen testuinguru etnografikoetako bat Gernika (Bizkaia) izan da. Espainiako Gerra Zibilean, tropa nazionalek Bilborako hurbilketan Ipar Frontean egin zuten erasoaldiak
Bizkaiko udalerri askoren bonbardaketa ekarri zuen, eta horien artean 1937ko apirilaren 26ko Gernikako bonbardaketa bereziki esanguratsua izan zen. Euskal askatasun tradizionalei lotutako hiribilduaren sinbolismoak eta euskal oroimen kolektiboan zuen esanahiak garrantzi handia eman zion nazioartean, eta horri nabarmen lagundu zion Pablo Picassok, sarraskiaren izugarrikeria irudikatuz, margotu zuen izen bereko lanak.

UNESCOk Bakearen eta Kulturaren Hiria izendatu zuen 2004ko udan, eta orain gatazken ebazpenen adibide paradigmatiko gisa aldarrikatzen da, bonbardaketa baten biktima izatetik bakearen munduko ikur izatera igaroz, bizipen traumatiko hari buruzko memoria eraikitzeko prozesu baten bidez. Trantsizio demokratikotik aurrera udalerri honetan, bai administrazioek bai herri-ekimenek jarraitutako memoria-politika bereziki goiztiarra izan da Euskal Autonomia Erkidegoaren testuinguruan, eta hondamendiaren eta gerraren sinboloa bakearen sinbolo bihurtzeko bokazio argia izan du. Zentzu honetan, memoria traumatiko baten ordez, memoria-dinamika bakezale eta antimilitarista bat aukeratu da, gatazken konponbidean sakontzen duena (Alonso Carballes, 2017). Laurogeiko hamarkadaren erdialdean argi egituratzen hasi zen prozesu horretan, hurrengo urteurrenek denbora-mugarri gisa funtzionatu dute, eta ekimen eta estrategia memoristikoak katalogatzen, azkartzen eta gauzatzen joan dira.

Horrenbestez, 1987an, bonbardaketaren 50. urteurrenean, alde batetik, Gernika gogoratuz bakearen aldeko ikerketa-zentroa sortu zen, hausnarketa zientifikoaren bidez mundu mailan eta bereziki Euskadin bake emantzipatzailea eta bidezkoa lortzen laguntzeko. Urte horretan aldi berean, denborarekin dimentsio monumentalak hartu izan duen espazio publikoaren monumentalizazio prozesu bat martxan jarri zen, 17.000 biztanleko hiribildu baten giza eskala nabarmen gaindituz. Orduz geroztik, Alonso Carballesek memoria-uholde geldiezin gisa izendatu duen prozesu horretan (2017:173), hiriko espazio publikoa bonbardaketaren biktimen omenezko hainbat monumentuz osatuz joan da.

Urtemugak data biribiletan nabarmentzeko joera horri jarraituz, 60. urteurrenean, 1998an Bakearen Museoa ireki zen, bakearen eta giza eskubideen kulturari eskainitako museo tematiko gisa, hiriaren gai historikoetatik abiatuta eta bonbardaketa tragikoan oinarrituta. 2002. urtean, Gernikako Udalak, Eusko Jaurlaritzak eta Bizkaiko Foru Aldundiak parte hartzen duten fundazio bihurtu zen, eta berriz egituratu ziren museoaren orientazioa eta erakusketa-edukiak. Berriztapen horren ideia nagusia museoak bakearen kultura eta Gernikako historia sustatzeko eta zabaltzeko edukiak eta dokumentazioa erakutsiko zituela izan zen. Birplanteamendu horrek museoari erantsitako bonbardaketari buruzko Dokumentazio eta Ikerketa Zentroari ere eragin zion, 2003an jarri baitzen martxan, eta Espainiako Estatuan gai horretako lehen museoa izan zen. 
Erakusketa-espazioaren birkonfigurazio berri hori lau solairutan egituratuta dago. Aldi baterako erakusketa-gela bat, gela didaktikoak, eta bakea eta giza eskubideak lortzeko ekimenen inguruko erakusketa iraunkor bat, hiru galderaren inguruan egituratuta: zer da bakea?; zer gertatu zen Gernikan bakerik gabe?; zer gertatzen da gaur egun munduko bakearekin?

Lehenengo solairuan, Gernikako bonbardaketari buruzko gogoeta, garai haietako etxe baten berreraiketa batekin osatzen da, Begoñaren etxearekin. Irrati-grabazio batek, isildutako ahots guztiak sinbolikoki biltzen dituen ahotsak eta bonbardaketaren soinuen erreprodukzioek denboran zehar lekualdatzen gaituzte, eta esperientzia emozional bizia eta biktimekiko enpatia sortzea lortzen dute. Hiriak hitz egiten digu izeneko ondoko gelan, Gernikako gerra zibila eta bonbardaketa dokumentatzen dira, eta kristalezko zoruak suntsitutako hiriaren arrastoak erakusten ditu gure oinen azpian. Biktimen historia ahaztua ardatz duen erakusketaren leit motiv-a adiskidetzea, elkar ulertzea, gatazkak gainditzea, bakea eta giza eskubideak dira, egiaren, justiziaren eta erreparazioaren bilaketa alde batera utzi gabe.

Proiektuaren izaera adiskidetzaile eta pedagogiko hori kritikatuta izan da, bonbardaketaren eta haren ondorioen alderdi belikoen azalpen zehatzagoa emateko joera handiagoa duten sektore politikoen aldetik ${ }^{4}$. Bai eta memoria aldarrikatzaileago sortzeko joera dutenek ere, borroken memoria-berreraiketa batzuen ildo beretik; izan ere, gerrari buruzko balizko hausnarketa bakezalea baino gehiago, gerrari buruzko memoria "berregin" egiten dute zentzurik zabalenean.

Museoak, bertako turismo bulegoarekin batera, bisita gidatuak antolatzen ditu Memori Tour lelopean, arestian aipatutako monumentu eta memoria gune guztiak lotzen dituen ibilbide batzuekin. Era berean, bisita gidatuak antolatzen ditu hiriko hainbat tokitan berreraiki izan diren aireko babeslekuetara. Zentzu horretan, Bakearen Museoaren 20. urteurrena zela eta, museoak, beste erakunde batzuekin lankidetzan ${ }^{5}$, Gernikako Foruen plazan bonbardaketaren aurreko egunetan herrian bizi izandako bizitzaren birsortze historikoa antolatu zuen, Gernika udabarri haretan.

Antzerki-ibilbidea hainbat espaziotan egituratzen zen, garai hartako eguneroko bizitzako eszenak birsortuz eta ordena tematiko bati jarraituz (ospitale bat, haurrak erbestera irteteko gizarte-laguntza postu bat, babeslekuen eraiketa, Ertzaintzaren postu bat). Horrela, gerra eguneroko bizitzan ustekabean sartzeak zer suposatu zuen irudikatzen saiatu ziren. Antzerki-ibilbidea Gernikazaharrako kideek plazatik hurbilen zeuden babeslekuetara egindako bisitarekin amaitzen zen. Pertsonaien karakterizazioak eta antzerkigintzak ekintza hauei nolabaiteko folklore-kutsua ematen zien, birsortzean jarrera ludiko batek elikatzen zuena.

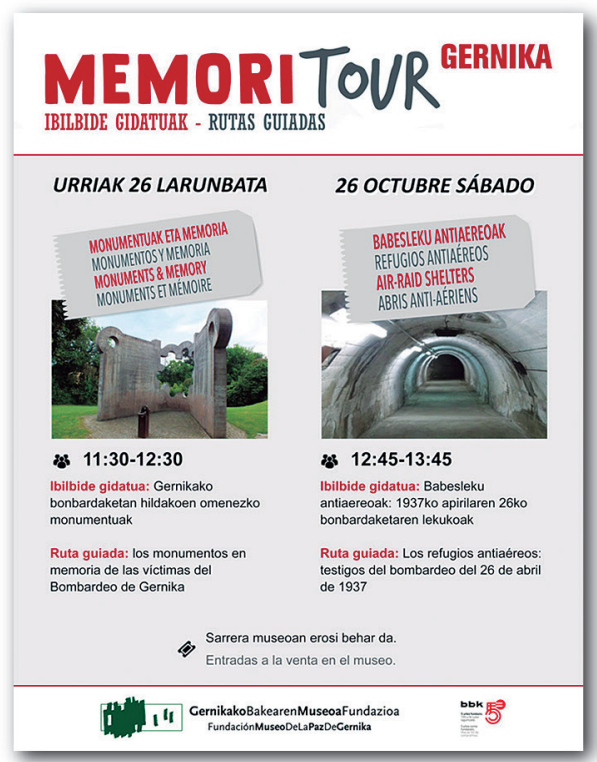

Fig.8. Memori Tour kartela, Gernikako babesleku antiaereo eta toki esanguratsuetatik ibilbidea. / Poster Memori Tour, Tour of the bomb shelters and other prominent places.

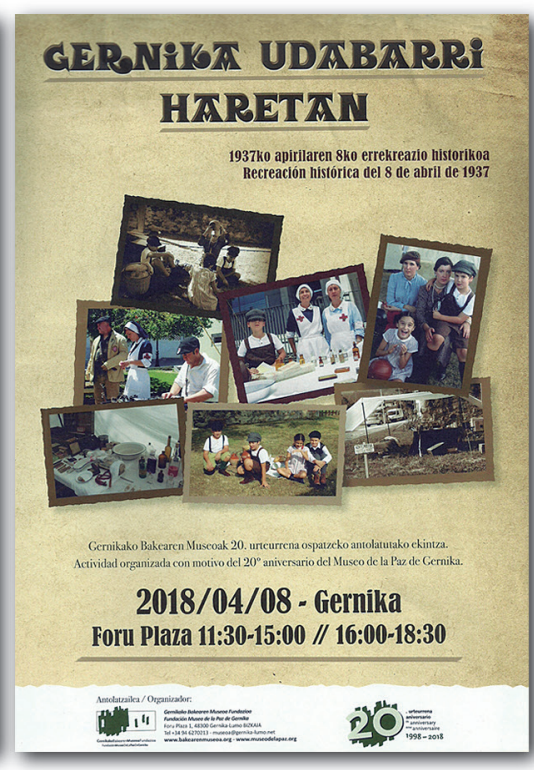

Fig.9. Gernika udabarri haretan, antzezpenaren kartela. / Poster of the theatrical representation Gernika udabarri haretan.

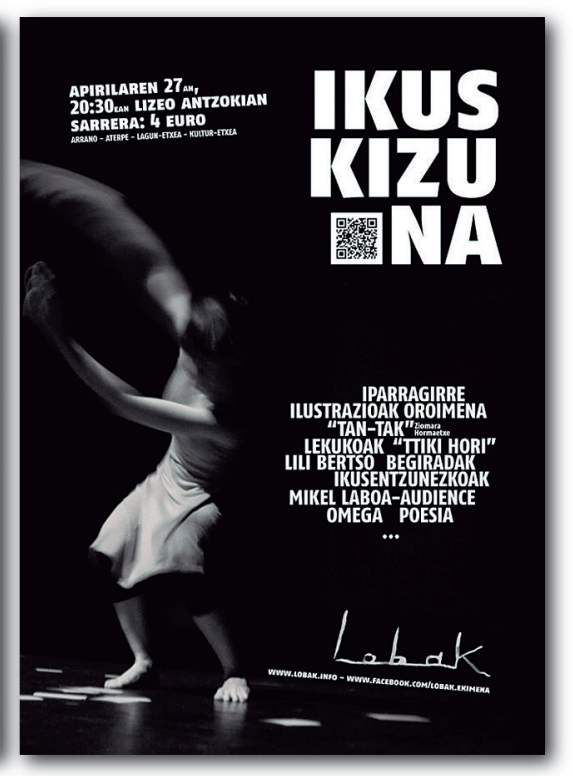

Fig.10. Lobak antolatutako ikuskizunaren kartela. / Poster of the show organized by the Lobak association.

\footnotetext{
4 Al museo de Gernika le falta ser museo del bombardeo, Iñaki Anasagasti-ren bloga, 2016ko urtarrillaren 7. / The Gernika Museum misses to be a Museum of the bombing. Blog of Iñaki Anasagasti, 7 of January, 2016. http://blogs.deia.eus/anasagasti/2016/01/07/al-museo-de-gernikale-falta-ser-museo-del-bombardeo/comment-page-1.

${ }^{5}$ Gernikazaharra historia taldea, Cinturón de Hierro Asociación Sancho de Beurko, Frentes de Euskadi, Lubakikoak, Gernikako udala eta BBK, eta Gernikako auzotarrak. / The Old Gernika Research Group, Iron Defense Sancho de Beurko Association, War Fronts of Euskadi, Trenchs Association, Gernika City Council eta the Village Dwellers of Gernika.
} 
Herriko antzezpen historiko horietako batzuetan ${ }^{6}$, gerra azpimarratzen duen ikuspegi militarista nagusitzen da. Kasu hauetan, behatzaileak nolabaiteko disonantzia bat aurkitu ahal du, gogora ekarritako gertakarien izaera tragikoaren eta izaera folkloriko eta askotan ludikoa islatzen duen errepresentazio baten artean. Eta era berean, gogoeta bakezalea elikatzen duten elementuak faltan bota.

Espazioaren monumentalizazioaz, museografia-praktikaz eta gatazken konponbideari eta bakerako estrategiei buruzko ikerketaz gain, izaera nagusiki artistikoa duten herri-ekimen memoristiko hauek ere gehitu dira: errepresentazio historikoak (lehen aipatutako Gernika udabarri haretan), bonbardaketaren antzezpenak (Gernika sutan edo Gernika garretan), biktimen oroimenez egindako espazioko erritualizazioak, edo adierazpenak, (Lobak), dantza garaikidea, musika, pintura edo Picassoren margolanaren birsorkuntza biziduna hartzen dituztenak, eta memoria honen belaunaldien arteko transmisioan lan egiten dutenak, bonbardaketa eta gerra bizi izan zituzten aitona-amonen testigantza jasoz, berreginez eta memoriari buruzko narrazio bat sortuz hainbat diziplinaren bidez. Dinamika horretan ere aipatzekoak dira, alde batetik, abandonatutako Astra arma-fabrika kultur zentro autogestionatu bihurtu izana, eta, bestetik, Bakearen eta adiskidetzearen aldeko Gernika saria eta Udalak urtero ematen duen Gernika Bake Kazetaritzaren alde George Steer saria.

Gernikako bonbardaketaren oroimenaren ondare kulturalaren prozesuan, hamabi monumentu, eskultura edo erreprodukzio artistiko eraiki dira herriaren espazio publikoan orain arte, urteurren aipagarrienek osatu izan duten daten inguruan kronologia horri jarraituz:
1. (1987) Bonbardaketan eroritakoak gogoratzeko hilarria, Ferialean (50. urteurrena).

2. (1988) Gure aitaren etxea (Chillida), Europako herrien parkean, eskultura monumentala (50-51. urteurrena).

3. (1990) Large figure in a shelter (Henry Moore), Europako herrien parkean, eskultura monumentala (53. urteurrena).

4. (1995) Bonbardaketaren biktimei eskainitako tenpletea hilerrian, kanpaiarekin eta gudarien izenekin (58. urteurrena).

5. (1995-2015) Gernika gudarosteari gorazarrea, 2. Mundu Gerran parte hartu zuen Gernika Gudarien Batailoiaren omenezko horma-irudi eskultorikoa; monumentu-multzoa fase ezberdinetan osatu izan da

6. (1997) Gernika Picassoren margoaren erreprodukzioa (60. urteurrena)

7. (1997) Marimeta, tamaina ertaineko eskultura (60. urteurrena).

8. (2006) George Steer, kazetariaren omenezko busto txiki bat; 69. urteurrenean kokatu zen.

9. (2011) Monument Aux Martyrs d'Oradour, kobrezko eskultura; Europako Herrien Parkean kokatu zen bonbardaketaren 74. urteurrena zela eta.

10. (2012) Suak eragindako agonia Nestor Basterretxea, San Juan parkina, eskultura monumentala (75. urteurrena).

11. (2017) Labairuaren bustoa (2012, 75. urteurrena). Lekukoak eta Labairua plaza (80. urteurrena).

12. (2018) Gudarien omenez Pase-Leku, tamaina ertaineko eskultura (81. urteurrena).

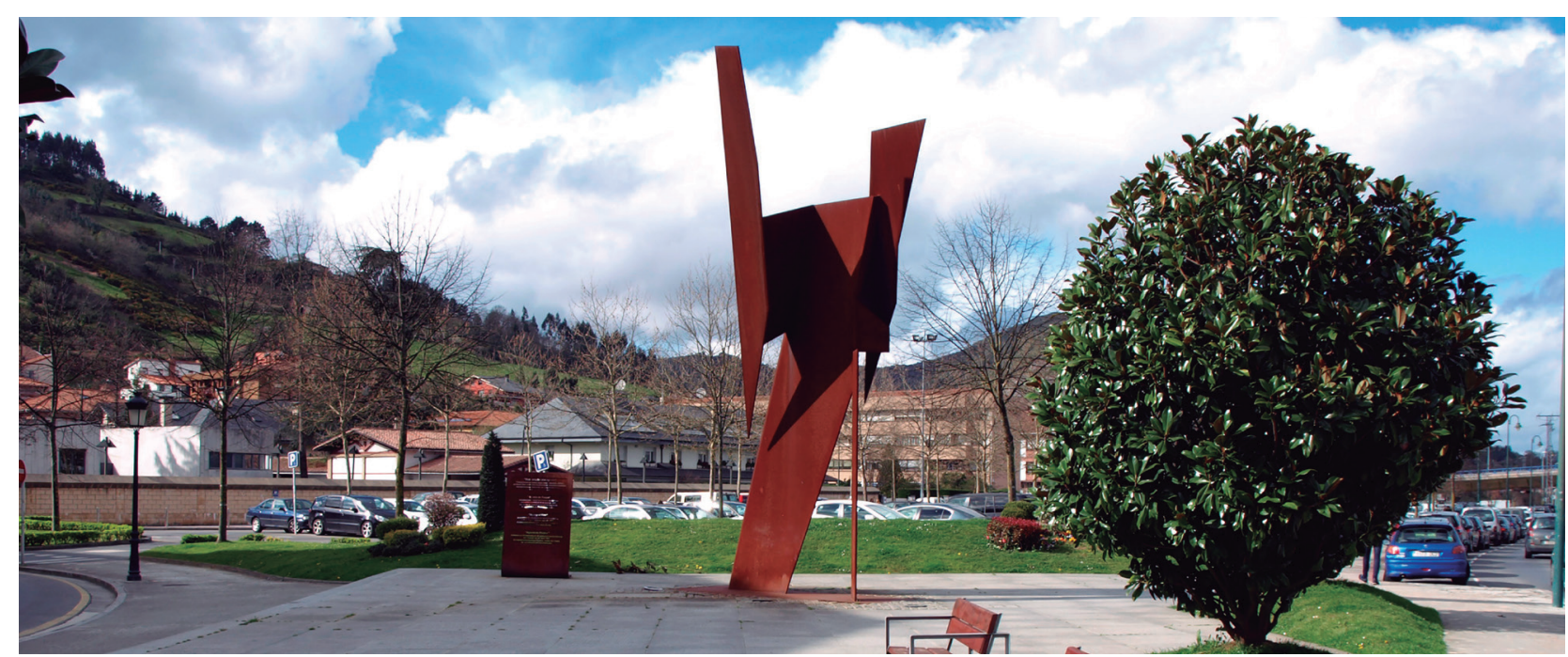

Fig.11. Nestor Basterretxearen Suak eragindako agonia, Gernikan (autorea, K. Fernández de Larrinoa). / Agony brought by Fire sculpture in Gernika, Nestor Baseterretxea (Photograph by K. Fernandez de Larrinoa).

\footnotetext{
${ }^{6}$ Horrelako beste adibide batzuen lekuko izan gara ikerketa honen beste testuinguruetan, adibidez Elgetan. / During our research we have found similar cases in other places in the Basque Country. For example, in the village of Elgeta.
} 


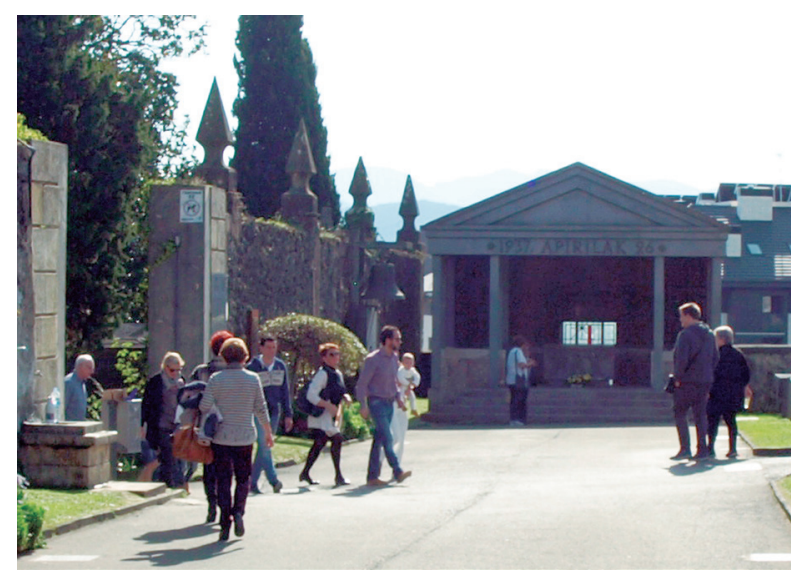

Fig.12. Tenpletea bonbardaketan hildakoen oroimenez (autorea, D. Rementeria). / Templet in remembrance of the deceased as a consequence of the airplane bombarding (Photograph by D. Rementeria).

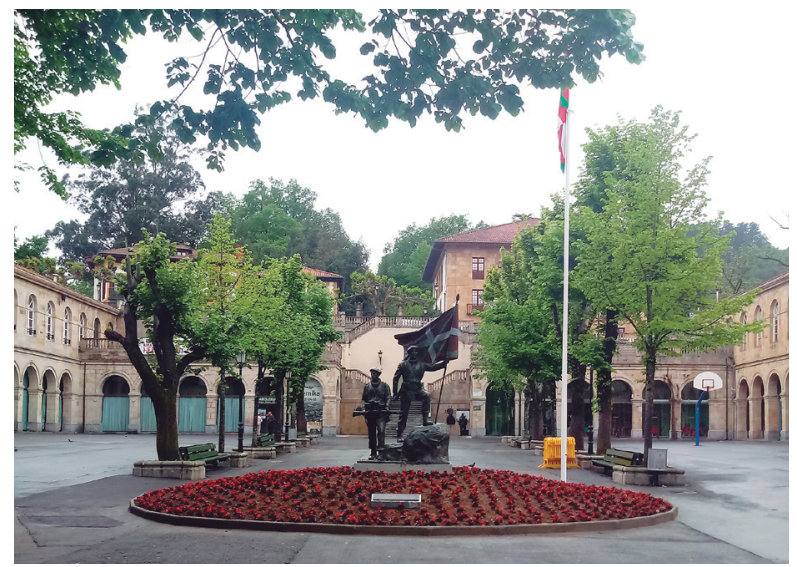

Fig.13. Gudarien omenezko eskultura Gernikako Pase-Lekuan (autorea, D. Rementeria). / Sculpture in remembrance of the Basque soldiers, Pase-Leku Square, Gernika (Photograph by D. Rementeria).

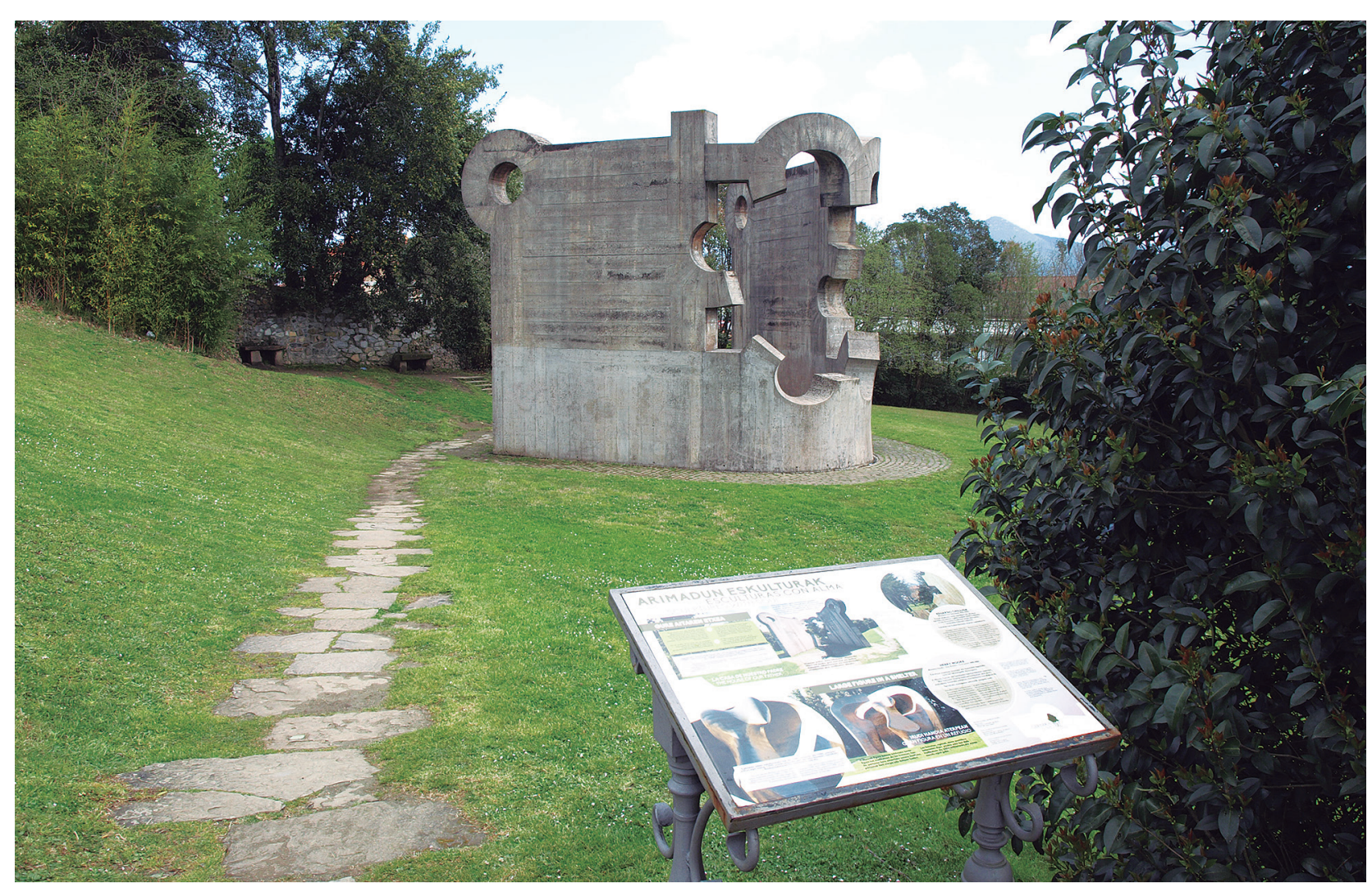

Fig. 14. Chillidaren Gure aitaren etxea, eskultura (autorea, D. Rementeria). / The sculpture Our Father's House, Eduardo Chillida (Photograph by D. Rementeria).

Bonbardaketaren biktimen oroimenez jarri zen lehen eskultura izan ezik, Ferialeko hilarria, tamaina txikikoa eta diskretu samarra dena, gainerakoak izaera monumentaleko eskultura edo erreprodukzio artistikoak dira. Eskultura eta monumentuez gain, bonbardaketan erabili ziren babeslekuak berreskuratu dira elementu turistiko gisa. Eskultura eta monumentu horien guztien memoria, biziraun dutenen irudia eta haien memoriaren transmisioa ditu ardatz, bizitza eta bakearen balioetan (Alonso Carballes, 2017:183).
Espazio monumentalen sare horren gainean sortutako ibilbide turistikoek, ikuspegi bakezalea izanik, hiribilduaren espazioan eraikitako paisaia memoriala eta sinbolikoa osatzen dute, bonbardaketak eta gerrak ekarri zuten tragediaren memoria gorpuzteko. Eta interpretazio-testuinguru batean aurkeztuta eta turismoaren ikuspegitik aktibatuta, memoria historikoa, jarduera ekonomikoaren eta tokiko garapenaren katalizatzaile gisa kokatzen dute. 


\section{MEMORIAREN TURISMOA}

Espainiako Estatuan memoria historikoari dagokionez gertatu den arketipo-aldaketa hori, beraz, batetik nonahi agertzen zen Caidos por Dios y por España-ren memoriatik, frankismoak hildako biktimen eta errepresaliatu politikoen memoria birjartzera doan igarobidean laburbiltzen da. Horren ondorioz, memoriaren hainbat leku balioan jarri dira, eta ondare bihurtu. Tokiko eskalan, praktika kulturalen multzoak diseinatu dira, eta horietako askok lurraldearen garapen ekonomikorako tresna gisa aurrez pentsatutako programa turistikoetan amaitu dute.

Katalunia aitzindaria izan da Espainian, Estatuaren administrazio-aparatuari esker Frantzian loratu izan den eredu horren aplikazioan (Cavaignac eta Deperne 2003). David Gonzalez Vazquez irakasleak adierazi duenez, "Diskurtso historiko bati eta turismoa balioztatzeko estrategia bati lotutako memoria-lekuen sare bat sortzea" da helburua. Paradigma kultural hori deskribatzeko memoria-ondarea eta jarduera turistikoa elkartzen dituen terminoa erabiltzen da, tourisme de memoire (Gonzalez Vazquez 2014, 2016).

Pierre Noraren arabera, memoria-espazio bat (dimentsio materialean, sinbolikoan eta funtzionalean) gertaera tragiko batekin lotutako leku bat da (Bourgon 2013). Mugaketa espazial horren barruan iragan traumatikoen oroitzapenak pizten dira. Espazio horiek sustatzeak eta aktibatzeak haien "bisitagarritasuna" garatzea dakar, herritarrentzat erakargarriak izan daitezen eta hauek bisita eta ezagutu ditzaten. Hori frankismoaren bidegabekerien memoria historikoa berreskuratzeko a priori bat bihurtu da. Hori dela eta, garapen ekonomikorako tokiko politiken eta memoria-espazio horiek adierazten dituzten balioak sustatzeko eta hedatzeko kultura-politiken artean dago, edo mugitzen da, memoriaren turismoa. Egoera biak estuki lotuta daude elkarren artean, eta, modu eraginkorrean, gerta liteke bata bestea gabe ulertzerik ez izatea (Hertzog 2013). F. Cavaignac eta $H$. Deperne frantsesek, beren herrialdean "tourisme du memoire" delakoaren ezarpen instituzionalaren prozesua aztertu dutenek, honela definitzen dute:

El turismo de memoria puede ser definido globalmente como la práctica que incita al público a explorar los elementos patrimoniales puestos en valor, para así extraer todo el enriquecimiento cívico y cultural que nos proporciona la referencia al pasado (Cavaignac eta Deperne, 2003: 14) ${ }^{7}$.

Horrela, memoria-turismoak lau dimentsio nabarmentzen ditu: alde batetik, demokraziarako normalizazio politikoak erregistratzen ditu; bestetik, lekuaren historia politiko-kulturala ondare-balioan jartzen du; bestetik, kultura bestetasuna in situ ezagutzeko eta esperimentatzeko beharrizan post-modernoak elikatzen ditu; eta, azkenik, tokiko garapenerako ardatz bilakatzen ditu bisita kulturalak.

Nabaritzen da, beraz, memoria-espazio horiek, lehenik eta behin, ondare bihurtzen direla, bigarrenik, ustekabeko bidaiariari iragartzen zaizkiola, eta, hirugarrenik, balio etiko eta moralen transmisioaren hezkuntza-lan trinko bat hedatzen dela.

Ondorioz, helburu ugari dituzte, besteak beste: belaunaldien arteko memoria-transmisioa ziurtatzea; biktimengan erreparazio-efektua lortzea; beren muga fisikoen barruan bizitza erritual eta sinbolikoa aktibo mantentzea; herritarren heziketa piztea eta bisitarien artean kontzientzia etikoak piztea; eta, aldi berean, hazkunde ekonomikoaren indizeetan eragitea.

Turismo masiboko egoerek, memoria-espazioen funtzio hezitzaile eta konpontzailearen kaltetan, aurrerapen ekonomikoa eta aberastasun materialaren areagotzea nabarmentzen dituzte, etengabeko mehatxua ekarriz: hots, tokiko memoria politiko eta kulturala hutsaltzeko arriskua. Hala ere, badira memoria-turismoaren propietate positiboak egiaztatzen dituzten hausnarketak egiten dituzten ikertzaileak ere:

la teoría al respecto de los usos turísticos de la memoria como un elemento de difusión cívica y pedagógica, contradice este peligro de banalización, y convierte al turismo de memoria en una herramienta más para concienciar a las sociedades sobre el respeto a los valores de la libertad y la convivencia (González Vázquez, 2016: 1277).

Memoria-espazioen banalizazio turistikoaren arrisku horri aurre egiteko, beharrezkoa da interpretazioeta metodologia-trebetasunak izatea, memoria-espazioaren oinarri duen kontakizuna etengabe indartuko dutenak. Olivier Lalieu historialariak honela azaldu du: "espazio bat gordetzean datza, bisita arrazionalaren ibilbidea garatuz eta sentsibilizazio- eta ezagutza-baliabide museografikoak sortuz" (2003: 29).

Gernikaren kasuan, estrategiak hainbat elementu biltzen ditu: museo espezializatu bat eta erreferentziazko erakusketa-zentro bat; artxibo eta dokumentazio-zentro bat; bakearen aldeko ikerketa-zentro bat (Gernika Gogoratuz); tokian toki berreskuratutako hainbat ondare-mota (babeslekuak, bunkerrak, dolu-espazioak eta hobi komunak); memoria-monumentu ugari; seinaleztatutako ibilbideak; lekukotasun-guneen berri ematen duten oroitzapen-markatzaileak; herri-ekintzen multzoak; administrazio-ekimenak.

\footnotetext{
7 Gaztelaniako itzulpena honako honetatik hartu dugu: González Vázquez (2016). / Translation into Spanish gathered from González Vázquez (2016).
} 


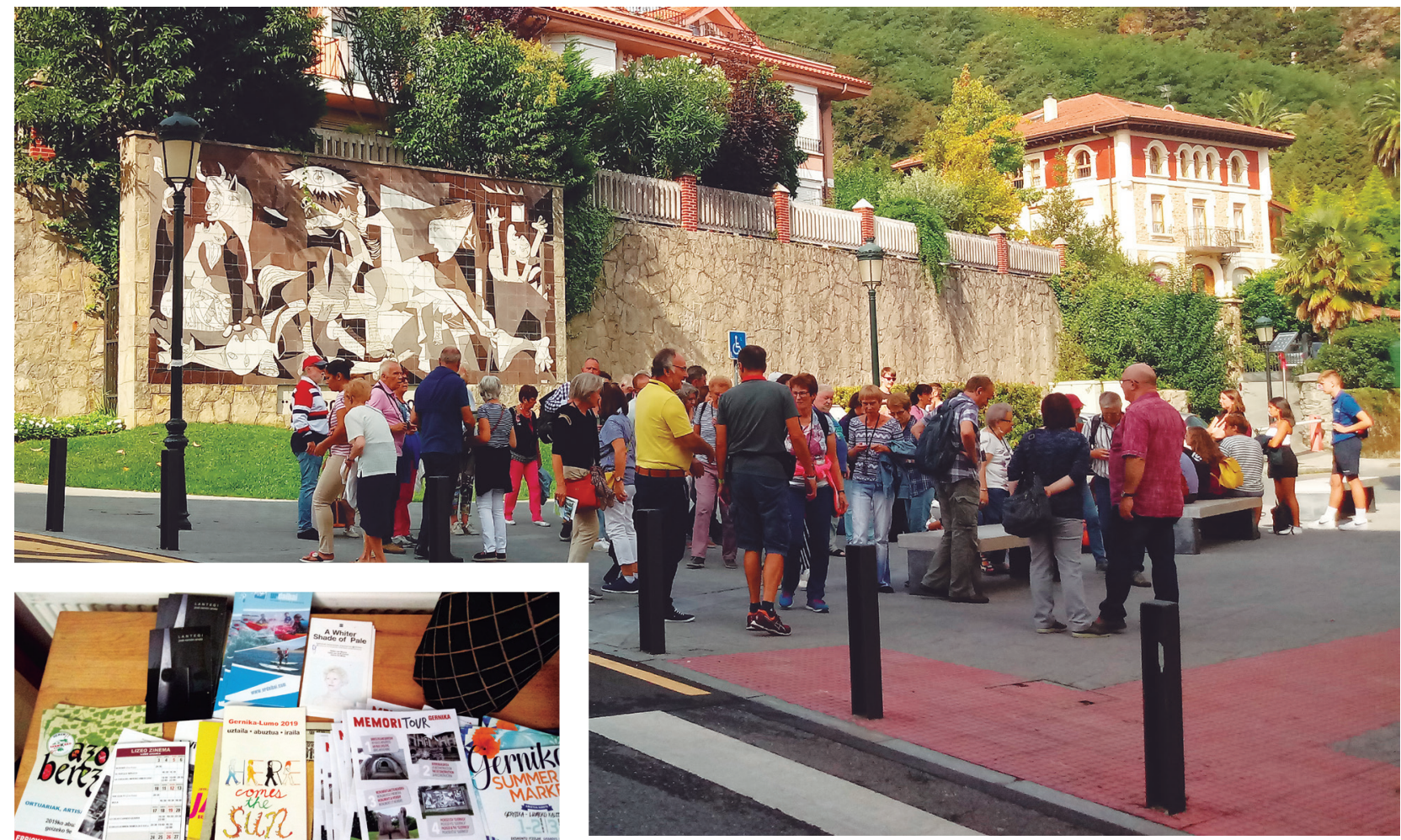

Fig.16. Turista talde bat Picassoren Guernicaren erreprodukzioaren aurrean Gernikan (autorea, D. Rementeria). / A group of tourists at Picasso's Guernica picture reproduction in Gernika (Photograph by D. Rementeria).

Fig.15. Gernikako eskaintza turistikoaren liburuxkak (autorea, D. Rementeria). / Stall with booklets and information sheets presenting possible touristic visits (Photograph by D. Rementeria)

\section{TOKIKO KULTURAK ETA DISTRAKZIO KULTU- RALAREKIKO ATXIKIMENDU POSTMODERNOA}

Antropologoek azaldu dutenez, tradiziotik modernitaterako bidean, talde soziokultural askok galdu egin dute aurretik zituzten ezagutza eta ondare kulturala (Ferro ed. 2003). Arrazoi nagusiak hauek izan dira: Iparraldeko nazioek Hegoaldean ezarritako ekonomia eta erlijio mendebaldetzerako politikak, eta Iparraldeko herrialde horiek euren barnean bertan egindako industrializazio eta batasun nazionalerako politikak. Horregatik gaur egun tokiko kultur ondarea indartzeko azpiegiturak ezartzea azpimarratzen da (Fernandez de Larrinoa ed. 2000). Horren arrazoia da aurreko belaunaldien ondare kulturalak berreskuratu nahi izatea, transmisioa eten baitzen kanpoko talde sozial eta ekonomikoek, boteretsuek edo eraginkorrek egindako presioaren ondorioz (Sider 1994; Meyer 1994; Dahl, Hicks eta Jull eds. 2000). Horixe da hain zuzen ere, gure ikerketan aztertutako memoria historikoko museo eta proiektuen zentzua.

Izan ere, kultur ondarearen kontzeptua aldakorra da, kulturaren kontzeptua ez baita konstantea (Austin-Broos ed. 1987; Alexander eta Seidman eds. 1990; Jenks 1993). Horren arrazoia da esanahiz aldatzeko joera dagoela antropologiako, etnografiako eta folklo- reko azterlanen ezaugarri diren eduki-aldaketen, analisi-perspektibaren eta kezka akademikoaren arabera, berauek ere orientazioa aldatzen baitute garaiaren eta lekuaren arabera (Herzfeld 2001; MacClancy ed. 2002).

Argudio nagusira itzuliz, gogora dezagun XX. mende amaierako kultura, kultur ondare eta (antropologiako) museo nozioek aurreko urteetakoen oso bestelako kezkak islatzen dituztela. Ikusi dugunez, gaurko museo etnografikoek tokiko memoria kolektiboaren museo gisa aurkezten dute beren burua. Bestalde XIX. mendeko eta XX. mendearen hasierako museoak metropolietan sortuak zirela, eta itsasoz haraindiko kolonietako kulturak eta estatu kolonizatzaileen barruko eskualde-periferiak ordezkatzeko ekintza esklusiboa gauzatzeko ahalmena zuten.

Gaur egun, garai hartan kolonia ekonomiko eta irudikapen folkloredun eta etnografiadun besterik ez ziren herriek eta eskualdeek sustatzen dute museoen eta kultura-zentroen sorrera; beraz, irudiak sortzeko eta kultura-irudikapenerako estrategiak diseinatzeko orduan, lehen ez zuten protagonismoa hartu izan dute (West ed. 1994; Clavir 2002; Kreps 2003; Brascoupe eta Mann 2004; Stanley ed. 2007). Hala ere, menperatze sinboliko eta komunikatiboaren arriskua eta mehatxua ez dira desagertu. 
Horrela, azken bolada honetan herri txikietan eta kultur talde minoritarioetan sortutako etnografia-museo askok helburu hirukoitza dutela ikus daiteke: 1) kultura gutxitu horiek beren burua ordezka dezaketen sorkuntzarako espazioak izatea; 2) kultur jardueren katalizatzaile gisa jardutea komunitatearen barruan; eta 3) politika homogeneizatzaileen ondorioz kaltetutako kultur nortasuna osatzen laguntzea.

Eta XXI. mendean krimen politikoaren museoen sorrera nabarmentzen da, bereziki ideologia eta erregimen totalitarioetatik babestutako hilketa eta tortura sistematikoarena. "Egia historikoaren" eta "giza sufrimenduaren" museo gisa aurkezten dute beren burua, eta bilduma museografikoak, dokumentazio historikoa eta pedagogia morala biltzen dituzte. Baina ez dira horregatik politikoki errugabeak (Sodaro 2018). Beraz, gaur egun eztabaidarako gaia nagusi bat bilakatu da, gizarte taldeen kultur jabetza diren arte- arkeologia-, etnografia-piezak, eta arbasoen arrasto fosilak jatorrizko komunitateei itzultzearena (Edson ed. 2007; Sullivan eta Edwards eds. 2004). Gernikarren kasuan, Pablo Picassoren Gernika koadroa moralki Gernikako herriarena den ala ez den, bilakatu da eztabaidaren ardatza; horrela izanik, Reina Sofia Museoak Madrilgo zaintzari uko egin beharko lioke eta Gernikan "aberriratzeko" euskal agintariei eman.

Azken aldian, ordea, beste jarrera batzuek hartu dute protagonismoa kultur ondareari buruz hausnartzeko orduan (kontsumismo ekonomikoa, tokiko garapena, demokrazia kulturala eta turismoaren hazkundea).

1980ko hamarkadatik aurrera, Europan, tokiko kultura-baliabideek garrantzi handia hartu dute gizarte postmodernoaren ekonomian, eta tokiko kultura-elementuak ondasun ekonomiko gisa aktibatzen dira sozialki. Horrenbestez, kultura-ikurren ekoizpen- eta kontsumo-aldi bat sortu da, non, alde batetik, kultura-bisiten sustapen turistikoa indarrean jartzen baita; bestetik, bisita horiek erraztuko dituzten azpiegituren instalazioetan. Horregatik agertzen dira ondare kulturalak han eta hemen. Izan ere, gizarte garaikidearen ezaugarrienetariko bat, etengabe kultura sinboloak sortu eta kontsumitzea, da.

Oraingo azterlanek berresten dutenez, gaur egun ondare kulturala-ren adierazpenak ez dio erreferentzia egiten iraganaren arrazionalizazio instituzionaleko prozesu bati. Bestela, egungo gizartearen egoera postmodernoari dagozkion praktika sozialen multzo bat sendotzen du. Interes handiagoa dute kultura-simulakroek, irudi, estilo eta estetika kulturalen aisaldi-sorkuntzak, honakoek baino: tokian tokikoan esleitutako ezagutzak, esanahiak, erantzukizunak eta portaera etikoak bereganatzen dituzten beharkizun kulturalek baino.

Europan, Marc Fumarolik estatu kulturalaren eredu frantsesa aztertu du, eta agerian utzi ditu kulturaren artifizioa eta ondare kulturalaren artefaktuarekiko harremanak. Autore horrek kezkatu egiten da kultura-estatuetako administrazioek eta haien goi-mailako hezkuntza-zentroek azkenaldian sustatzen duten onda- re-eskolastikari begiratzen dionean; izan ere, hauek harrotu egiten baitira kultura-politika demokratiko eta horizontalak herritarren zerbitzura sustatzeaz arduratzen direlako, hausnarketa-hezkuntzarako eta sormen-prestakuntzarako eskubidea bermatuz.

Kulturaren ondarizazio garaikideak beste helburu bat du -dio Marc Fumarolik-, hots, orientazio kontsumistako entretenimendu kulturala sustatzea, hau da, helburu merkantilista bat. Gaur egun, kultur ondarea aisialdi kolektiboen ekonomia politikoaren zati da (Fumaroli, 1991:287). Kultura "entretenimendu demokratikoaren" terminoetan patrimonializatzeak distrakzioaren industria kapitalista noranahi kateatzea dakar. Jakina, galdera hau da: Zertaz distraitzen gaitu kultur ondareak?

Dean MacCannell antropologo iparramerikarrak idatzitako Lugares de encuentro vacíos (1992) liburuak, distrakzio kulturalarekiko atxikimendu post-modernoa elikatzen duen egitura kognitiboa aztertzen du. Bertan, egileak subjektu post-modernoen identitate kulturala soziologikoki ulergarri bihurtzen duten gako semiotikoei heltzen die, eta jarrera post-modernoa berezitasun kulturala deuseztatzeko modu berri bat besterik ez dela argudiatzen du.

XIX. mendean, tokiko kulturak harrapatuta geratu ziren beren epistemologia eta ezagutzekin, garaiko europar inperioen hedapen kolonialaren sareetan. XX. mendean, politika eta estatu mailako bateratze-prozesuek eta industria-ekoizpeneko merkatu nazionalak mugatzeko prozesuek preso hartu zituzten. Hori guztia nazio-estatuaren egitura administratiboak sustatutako identitate komun moderno bat eraikitzeko prozesu baten barruan, barne-artikulazioko mekanismo gisa bultzatuta.

XXI. mendean, tokiko komunitateek bertan jarraitzen dute, irabazi-asmoko enpresa-ekintzaren beste une batekin batera, kapitalismoa berantiarra, kapitalaren hedapen globalaren egungo korolario gisa garatzen dena. Eta aurreko mendean garapen ekonomiko nazionalaren dogmak, komunitate indigenen proposamen kosmologikoen eta estatu-nazioaren ideologiaren artean zegoen hutsune soziokulturala bete nahi izan zuen bezala, gaur egun turismoaren doktrinak betetzen du hutsune hori.

1936-1939ko gerrako memoria historikoak arrisku bera du: besterentze kultural berri baten arriskua, gero eta zabalduago dagoen kultura- eta nortasun-merkataritzaren praktika ondorio dena. Espainian, memoria historikoaren nozioa 1936-1939ko Gerra Zibileko garaituen memoriaren sinonimo bihurtu da. Baita hego Euskal Herrian ere, Euskadin eta Nafarroan alegia. Hala ere, saiakera honetan ikusi dugunez, "Memoria historikoaz" hitz egitean, prozesu politikoetan txertatutako memoria kulturalez ari gara.

Horregatik, egokiagotzat jotzen dugu lurraldetasun politikoen memoria historikoen ondarizazio-prozesuei buruz hitz egitea. Prozesu horietan, kultura-irudikapen desberdinak aurkitzen ditugu. Saiakera honetan ikusi dugu Gernikako proiektu museografikoan nazioarteko- 
tasunaren, bakearen eta gatazkaren eta etorkizunaren irudiak gailentzen direla. Baina ez dira Urdaibaiko eta eskualdeko hirigintzaren barruan biltzen diren irudi kultural bakarrak.

Horrelako gune babestuetan ohikoa da kultura ondare bihurtzea, natura ondare bihurtzearekin batera. Ondarizazio bikoitz hori bultzada turistikoaren bidez aktibatzen da eta bi prozesu laburbiltzen ditu: natura kulturizatzeko prozesu dialektiko bat eta kultura naturalizatzeko prozesu dialektiko bat (Santamarina eta Bodí, 2013: 135). Garapen iraunkorraren ikuskera neoliberalaren babesean, bizitza sozial eta kulturalaren printzipio antolatzaile gisa, Gernika eta Urdaibaiko Biosferaren erreserbako eremu babestua merkatu-espazio bihurtzen ari dira. Post-estrukturalismo ekologikotik iradokitzen den bezala, azkenaldian nazioarteko erakunde politiko-ekonomikoetatik hedatutako iraunkortasunaren nozioa modernotasun euroamerikarraren "arrazionaltasun" produktiboa berrikusteko interes gutxiko diskurtsoan oinarritzen da. Aitzitik, 2000. urtean hain hedatua izan zen ekologia- eta ingurumen-jasangarritasunaren ideia hori, formalki hedatutako kultura-estrategia batean zehar doa industria-osteko aro honetan, XX. mende osoan mendebaldeko modernitatearen ezaugarri izan zen arrazionaltasun ekonomiko bera iraunarazteko asmoarekin (Peet eta Watts 1996).

Garapen iraunkorra marka kultural bat gehiago da. Helburu gisa pentsatuta dago, eta kapitalaren ekoizteko prozesu politikoki zuzenak ziurtatzeko helburuarekin sortu $\mathrm{da}^{8}$. Zentzu horretan, Biosferaren Erreserba bezalako logotipoek giza geografiaren orbitara heltzen dira erantzun kosmetiko gisa; hau da, herritarren artean astindutako gizarte-kontzientziako egoera berrietara estetikoki egokitzeko. Esan daiteke garapen jasangarria adierazpena, nazioarteko gobernu-erakundeen jabetze politiko-administratibo gisa sortzen dela. Erakunde horiek, jakin izan dute ekologia politikoaren ideiaren inguruan hasieran antolatutako gizarte-ekintzako korronte oso bat harrapatzen, ingurumen-aurrezpeneko proposamen kultural (eta finantzario) sofistikatu baten barruan? Nazioarteko erakunde horiek, oinarrizko mugimendu sozialen emariaz gain, ekintza ekologistaren oinarrian zegoen likido politiko eraldatzaile guztia xurgatzen jakin dute. Horrekin pozik ez eta, ebasketaren ondoren, koloreztatutako administrazio-hizkera berezi bat bueltan isuri dute gizartera. Hizkera horren bereizgarria da "paisaia-produktuak" edo "gertaera ekokulturalak" sustatzea, emozio pertsonalen eta gizarte post-moderno eta berantiar-kapitalisten barne-asebetetzearen merkatu berrian sartu ahal daitezen. Beste era batera esanda, gizarte-sustraiko pentsamendu ekologikoa, gaur egungo bidaia turistikoaren berezko jarduera kontenplatibo, ludiko eta entretenigarrien lurralde-antolaketaren mendean dago.

Gerraren eta Gernikako bonbardaketaren memoria historikoa, paisaia naturalarekin, gastronomiarekin, mendi-ibilbideekin, itsasoko bainuekin eta jai-ospakizun vintage-ekin batera, kultur dinamika mota honetan txertatuta dago. Trauma, iraunkortasuna eta nortasunaren irudi kulturalak, produktu turistiko huts bihurtzeak ekarriko lukeen hutsalkeriaren eraginpean daude. Negozio-aukerak sor ditzaketen gizarte- eta kultura-bizitzaren alderdi guztiak merkaturatzearen aldeko presio horren aurrean, kultur ondarea balioan jartzearen jarrera dago, eta, beraz, memoria historikoa ere, gizarte-erabilerako balioaren arabera, hau da, jatorrizko komunitateen ezaugarri diren gizarte- eta politika-harremanen multzoaren arabera duen esanahi sinboliko eta identitarioaren arabera. Ezagutzaren adar guztietako kudeatzaileek, adituek, ekonomialariek eta zientzialariek ondarearen eraiketa/eraikitzaile binomioan "aurkitu" ditzaketen kultura-elementuen materialtasunaz, ikusgarritasunaz eta errentagarritasunaz haratago, oinarrizko gizarte-ekintza dago.

\section{LABURBILDUZ}

Saiakera honetan, hausnarketa antropologikorako esparru bat aurkeztu dugu, eta memoria historikoa berrezartzea bultzatzen duten euskal herritarren mugimenduei lotutako irudikapen kolektiboak eraikitzeko egungo prozesua aztertzeko orduan egokia dela defendatu dugu. Antropologia sinboliko eta politikoaren arteko eremuan kokatutako argudiatze-lerro bat formulatu dugu, eta gai horren egokitasuna kontuan hartzera gonbidatu dugu, baldin eta gaiak etnografia dialektikoak egitea eskatzen badu sinbolo, pentsamolde, erakustaldi eta erakusketa publiko, kaleetako talde-dramatizazioak, erritu-zeremoniak eta 1936ko Gerraren memoria historikoaren inguruan sortzen diren gainerako adierazpen eta irudikapen kulturalen munduan barneratzeko. Era berean, hiru azterketa-eremu nagusi eta horien interkonexioak egiaztatu ditugu. Eta adierazi dugu gizarte zibil antolatuak memoria historikoaren berrezarpen publikoaren aldeko politika instituzionalak ezartzearen alde lan egiten duten tokiko elkarteen inguruan egiten duen erabilera eta interpretazioa batera aztertu beharreko gaia dela.

Bigarrenik, iraganeko irudiak, sinboloak, kultura-adierazpenak eta esanahi historiko-memoristikoak sortzeko egungo prozesuari laguntzen dioten esanahi politikoen dinamismoa eta dialektika aztertzeari ekin diogu. Eta, hirugarrenik, memoria historikoari eta Gernikako egia eta justizia politikoaren egungo berrezarpena eta errekonozimenduari buruzko memoriaren lekuen,

\footnotetext{
${ }^{8}$ Hobe esango genuke, «alegiazko» zuzenak. / We would better say «supposedly» correct.

${ }^{9}$ Hemen aipatzen dugun ekologia politikoaren nozioa antropologia sozialaren azterketekin nola lotzen den jakiteko azterlan bat hemen aurkitu ahal da: Comas D'Argemir (1999). / For further detail in the Spanish language on the notion of political ecology at work within social anthropology studies to which we are referring here, see Comas D'Argemir (1999).
} 
erritu-zeremonien, erakusketen eta bestelako kultura-adierazpenen zerrenda etnografikoa aztertu dugu. Aurrekoak esparru eta dimentsio kultural espezifikoak dakartzaten eremuak dira, normalean ezagutza historikoa/herentzia kulturala eta haren transmisio soziala binomioan ulertuak. Izatez, hauek dira hain zuzen: esparru eta dimentsio kultural administratiboa; esparru eta dimentsio kultural historiko-politikoa; esparru eta dimentsio kultural antropologikoa; esparru eta dimentsio kultural etnografikoa.

Beraz, 1936-1939ko gerran garaitutakoen aldeko memoria historikoa berrezartzen eta babesten parte hartzen duten tokiko elkarte zibilek egindako proposamenetan sortutako oroimenezko gizarte-errituak eta kultura-irudikapenak aztertu ditugu. Elkarte horiek antolatu dituzten gertaerek eta azpiegiturek garrantzi kolektibo, sozial eta kulturala dute, tokiko historia behar bezala ulertzeko; izan ere, diktadura frankistaren hamarkadetan erreprimitutako esanahiak eta emozioak gogorarazten baitituzte.

Bildutako ezagutzak gizakiok gure jakintza-mota desberdinak transmititzeko, sozializatzeko, ebaluatzeko eta eztabaidatzeko ezarri ditugun kultura-zirkuituen barruan daude. Jakintza transmititzeko eta sozializatzeko zirkuitu horien artean museografia eta erakusketa publikoak daude. Saiakera honetan argudiatu dugu museoek, plazek eta kaleek ez dituztela politikoki neutro diren espazio kulturalak antolatzen. Era berean, espazio horietan, ez da aurkitzen sozialki zehaztugabe den ekonomiarik ere.

\section{BIBLIOGRAFÍA}

Alexander, J. C., Seidman, S. (Eds.), 1990. Culture and society: contemporary debates. Cambridge University Press, Cambridge.

Alonso Carballés, J., 2017. Memorias de piedra y acero. Los monumentos a las víctimas de la Guerra Civil y del franquismo en Euskadi (1936-2017). Gernikako Bake Museoa, Gernika.

Ames, M. M., 1992. Cannibal Tours and glass boxes: the anthropology of museums. University of British Columbia Press, Vancouver.

Austin-Broos, D. J. (ed.), 1987. Creating culture. Allen and Unwin, North Sydney.

Bourgon, A., 2013. Les lieux de memoire, une valeur sociale plus que touristique. Cahier Espaces 313, 62-67.

Brascoupe, S., Mann H., 2001. A community guide to protecting indigenous knowledge. Department of Indians Affairs and Northern Development, Ottawa.

Brockmeier, J., 2018. Beyond the archive: memory, narrative, and the autobiographical process. Oxford University Press, Oxford \& New York (2015; rev. paperback version 2018).

Cavaignac, F., Deperne H., 2003. Les Chemins de memoire. Une initiative de l'Etat. Cahier Espaces 80, 12-21.

Chicote, J., 2017. Cataluña exporta la cuarta parte de armas y munición que vende España. Diario ABC, 2017ko abuztuaren 13.
Clavir, M., 2002. Preserving what is valued: conservation and First Nations. University of British Columbia Press, Vancouver.

Comaroff, J. L., Comaroff Jean, 1991. Ethnicity. Inc, University of Chicago Press, Chicago.

Comas D’Argemir, D., 1999. Ecología polítíca y antropología social. Áreas: revista de Ciencias Sociales, 19(1), 79-99.

Dahl, J., Hicks, J., Jull P., 2000. Nunavut: Inuit regain control of their lands and their lives. International Work Group for Indigenous Affairs, Copenhagen.

Dilworth, L., 1996. Imagining Indians in the Southwest: persistent visions of a primitive past. Smithsonian Institution Press, Washington D.C

Edson, G., (ed.) 1997. Museum ethics. Routledge, Londres.

Errington, S., 1998. The death of authentic primitive art and other tales of progress. University of California Press, Berkeley.

Fernandez de Larrinoa, K., 2003b. Sabor de antaño: notas sobre identidad local, actualización etnográfica y desarrollo cultural. Pamiela, Iruñea.

Fernández de Larrinoa, K., 2011. Manifiesto por una antropología razonada. El papel del antropólogo en el Estado neoliberal (Crítica cultural del desarrollo local y el patrimonio cultural europeos). Laminarra eta Lera-Ikergunea, Iruñea.

Fernández de Larrinoa, K., 2016b. La insolencia del método etnográfico en un país foráneo. Cuadernos de Etnología y Etnografía de Navarra (CEEN) 90, 331-380.

Fernández de Larrinoa, K., 2018. Trabajo social indígena en sociedades indígenamente conceptualizadas. Muñoz Sánchez, P., Vitón, M. J. (Eds.), Comunidad, desarrollo y escenarios colaborativos emancipadores: reflexionando la alteridad sociocultural, Compobell, Murcia.

Ferro, M. (Ed.), 2003. Le livre noir du colonialisme (XVle-XXle siècle): de l'extermination à la repentance. Editions Robert Lafont, Paris.

Fumaroli, M., 1991. L'État culturel. Éditions de Fallois, Paris.

Gonzalez Vazquez, D,. 2014. La práctica turística como mecanismo de transmisión de valores: Cataluña y los lugares de memoria democrática. RITUR Revista Iberoamericana de Turismo 4, 36-49.

Gonzalez Vazquez, D., 2016. La patrimonialización de la memoria histórica: entre el deber social y la estrategia turística. Apuntes sobre el caso catalán. PASOS. Revista de Turismo y Patrimonio 14(5), 1267-1280.

Halbwach, M., 1939. La mémoire collective. PUF, Paris.

Hertzog, A., 2013. Quand le tourisme de memoire bouleverse le travail de memoire. Cahier Espaces 313, 52-61.

Hertzfeld, M., 2001. Anthropology: theoretical practice in culture and society. Unesco y Blackwell Publishing, Oxford.

Jenks, Ch., 1993. Culture. Routldege, Londres.

Kalin, N. M., 2006. Consensus and Dissensus at the Neoliberal Art Museum. Knowledge Cultures 4(5), 28-42.

Kreps, Ch., 2003. Liberating culture: cross-cultural perspectives on museums, curation and cultural heritage preservation. Routledge, Londres.

Lalieu, O., 2003. Memoire de la Shoah. L'action du Centre de documentation juive contemporaine (CDJC). Cahier Espaces $80,27-31$ 
MacCannell, D., 1992. Empty meeting grounds. Routledge, Londres.

MacClancy, J. (Ed.), 2002. Exotic no more: anthropology on the front lines. The University of Chicago Press, Chicago.

Meyer, M. L., 1994. The White Earth tragedy: ethnicity and dispossesion at a Minnesota Anishinaabe Reservation (18891929). University of Nebraska Press, Lincon.

Milcu, A. I., Hanspach, J., Abson, D., Fischer, J., 2013. Cultural ecosystem services: a literature review and prospects for future research. Ecology and Society 18(3), 44. http://dx.doi. org/10.5751/ES-05790-180344.

Mitchell, P., 1997. Introduction to theory of mind: children, autism and apes. Edward Arnold Publishers, Londres.

Morphy, H., 1991. Ancestral connections: art and an aboriginal system of knowledge. The University of Chicago Press, Chicago.

Mosedale, J., 2016. Neoliberalism and the Political Economy of Tourism, Routledge, Londres.

Nora, P. (Dir.), 1984, 1987, 1992. Les lieux de mémoire, Gallimard, Paris.

Peet, R., Watts, M. (Eds.), 1996. Liberation ecologies. Enviroment, development, social movements. Routledge, Londres.

Rementeria Arruza, D., 2014. Performance y rito en los Marijeses de Gernika. Voces para la identidad. Jentilbaratz, Cuadernos de Folklore 15, 113-227.

Rementeria Arruza, D., 2015. Turismo y paisaje en la reserva de la biosfera de Urdaibai (Bizkaia). Representaciones y estrategias. Una mirada antropológica. International Journal of Safety and Security in Tourism/Hospitality, (IJSSTH). 11. Universidad de Palermo, Buenos Aires.

Rementeria Arruza, D., 2016. Paisajes culturales de Busturialdea. Procesos, tensiones y derivas. Kobie, Anejo 14. Bizkaiko Foru Aldundia. Bilbao.

Santamarina Campos, B., Bodí Ramiro, J., 2013. Lugares rurales versus espacios naturalizados. Conocimientos y reconocimientos en las lógicas patrimoniales de las áreas protegidas.
AIBR. Revista de Antropología Iberoamericana. 8(1), 111-138.

Sherman, D. J., Rogoff, I. (Eds.), 1994. Museum culture: histories, discourses, spectacles. Routledge, Londres.

Sider, G. M., 1994. Lumbee Indian histories: race, ethnicity and Indian identity in the Southern United States. Cambridge University Press, Cambridge.

Simpson, M. G., 1996. Making representations: museums in the post-colonial era. Routledge, Londres.

Sodaro, A., 2018. Exhibiting atrocity: memorial museums and the politics of past violence. Rutgers University Press, New Brunswick.

Stallabrass, J., 2007. Contemporary art in a neoliberal climate. Available from: http://www.worldofart.org/aktualno/archives/131.

Stanley, N. (Ed.), 2007. The future of indigenous museums: perspectives from the Southwest Pacific. Berghahn, Oxford.

Strother, Z. S., 1998. Inventing masks: agency and history in the art of the Central Pende. The University of Chicago Press, Chicago.

Sullivan, L. L., Edwards, A. (Eds), 2004. Stewards of the sacred. American Association of Museums, Washington D.C.

West, R. Jr. (Ed), 1994. All roads are good: native voices on life and culture. Smithsonian National Museum of the American Indian, Washington D.C.

Zallo, R., 2005. El Plan Vasco de Cultura: una reflexión. Revista Internacional de Estudios Vascos 50(1), 11-55.

Zallo, R., 2010a. El Contrato Ciudadano por las Culturas: un pésimo comienzo. Diario de Noticias de Gipuzkoa, iraila 23.

Zallo, R., 2010b. Análisis crítico del proyecto Guggenheim Urdaibai: 7 tesis a contraste y 5 propuestas. Gernika, urria 23. Disponible en: http://alkartasunafundazioa.eus/wp-content/ uploads/2011/05/El-proyecto-Guggenheim-Urdaibai.-Ramon-Zallo.-23-10-2010.pdf

Zulaika, J., 2002. Guggenheim Bilbao Museoa: Museums, Architecture, and City Renewal. Nevada University Press, Reno. 